\title{
فاعلية تدريس العلوم بمدخل STEM في تنمية مهارات البحث بمعايير ISEF لاى طلاب المرحلة الابتدائية
}

\author{
ماجد محمد حسن المالكي \\ إدارة تعليم جدة- المملكة العربية السعودية \\ Joojooo1985@hotmail.com
}

الملخص:

هدف البحث إلى التعرف على مدى فاعلية تدريس العلوم بوحدة الأنظمة البيئية وفق مدخل ستيم STEM في تتمية مهارات البحث العلمي بمعايير أنموذج Intel ISEF لدى طلاب الصف الخامس الابتدائي في جدة، وذلك للوقوف على مدى إيفاء تعليم مناهج العلوم بالمرحلة الابتدائية بالطموحات الوطنية في إكساب طلاب المرحلة الابتدائية مهارات القرن الحادي والعشرين، وبخاصة ولئ مهارات البحث العلمي. وقد تم إتباع التصميم شبه التجريبي لمجموعتين (تجريبية وضابطة) أُجري عليهما القياس القبلي والبعدي باستخدام اختبار مهارات البحث العلمي وفق معايير مسابقة Intel ISEF، حيث درس طلاب المجموعة التجريبية (0ب طالباً) وحدة الأنظمة البيئية باستخدام دليل المعلم بمدخل STEM لتتمية مهارات البحث وفق معايير إنتل أيسف Intel ISEF، بينما درس طلاب المجموعة الضابطة (0r طالباً) وحدة الأنظمة البيئية بالأساليب التدريسية المعتادة.

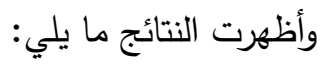

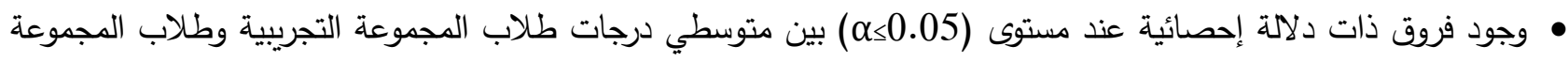

الضابطة في التطبيق البعدي لاختبار مهارات البحث العلمي وفق معايير مسابقة Intel ISEF، وذلك لصالح المجموعة التجريبية.

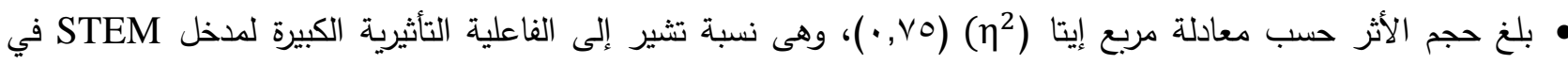
تتمية مهارات البحث العمي وفق معايير مسابقة Intel ISEF لذى طلاب الصف الخامس الابتدائي بجدة الذين درسوا وحدة الأنظمة البيئية وفق مدخل STEM. • عدم وجود فروق ذات دلالة إحصائية عند مستوى (5 م م) بين متوسطات معدل التحسن في مهارات البحث العلمي لدى طلاب المجموعة التجريبية ذوي المستويات المهارية المتباينة (مرتفع، متوسط، منخفض)، مما يشير إلى فاعلية دراسة وحدة الأنظمة

البيئية بمدخل STEM في تتمية مهارات البحث العلمي بمعايير Intel ISEF لدى الطلاب ذوي المستويات المهارية المتباينة. وبناء على نتائج البحث، تمت التوصيات بتعميم استخدام مدخل STEM في تدريس مناهج العلوم، لما له من فاعلية في تتمية

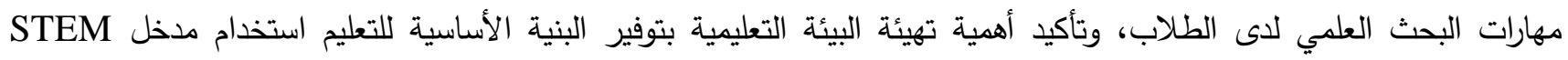

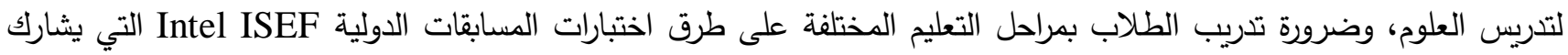


الكلمات المفتاحية: العلوم، المرحلة الابتدائية، ستيم(STEM).

\section{(a) (1)}

المقدمة:

يعيش واقعنا المعاصر تطورات متسارعة في المعرفة العلمية شملت مجالات الحياة المختلفة، الأمر الذي يشكل تحديًا كبيرًا للطلاب، والمعلمين، ومناهج التعليم عامة، وبخاصة مناهج العلوم بمراحل التعليم المتعددة. وقد أوجب ذلك على الأنظمة التربوية القيام بأدوار فاعلة لمراعاة هذا الزخم المعرفي المتنامي، والوفاء بإعداد أجيال متقنة لمهارات القرن الحادي والعشرين، وقادرة على التوافق مع التطورات العلمية المتسارعة، بأساليب تفكيرية إيجابية، تعكس تمكنهم من مهارات البحث العلمي، لمواجهة المشكلات الحياتية المتنوعة.

وتتطلب تتمية مهارات البحث لدى الطلاب عدم اقتصار مناهج العلوم على اكتساب المعارف العلمية للطلاب فحسب، بل يتطلب ذلك تهيئتها فرصًا تعليمية متتوعة، لمساعدة المتعلم على التنكير، وتتمية مهارات التعلم الذاتي لديه، ومن ثم تعزيز مقدرته على التعلم المستمر، وتوظيف ما اكتسبه من معارف، ومهارات، واتجاهات، وقيم، وأنماط تنكير إبداعي. وتحرص وزارة التعليم في المملكة العربية السعودية على مواكبة حركات إصلاح التربية العلمية، وذلك بتفعيل مبادرات تطويرية لضمان التحول النوعي في أداء النظام التعليمي السعودي، وتحقيق التطلعات المجتمعية المأمولة، وفق معايير دولية موثوقة.

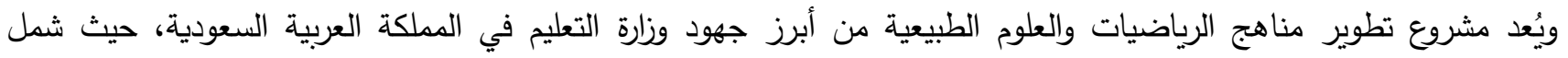
مواءمة سلسلة مناهج ماجروهيل العالمية، والمشاركة في الدراسة المقارنة الدولية للتحصيل في العلوم والرياضيات (TIMSS) بدوراتها المتتالية لتعزيز مقومات الثقافة العلمية Science Literacy لدى الطلاب (مشروع الملك عبد الله لتطوير التعليم،

وتشارك المملكة العربية السعودية في مسابقات دولية متعددة، كمحكات تقييمية لفاعلية أثر مناهج العلوم في تفكير الطلاب، وتتمية مهارات البحث العلمي لديهم، ومنها أولمبياد معرض إنتل أيسف (INTEL ISEF) للعلوم والهندسة، والذي أبرمت مؤسسة

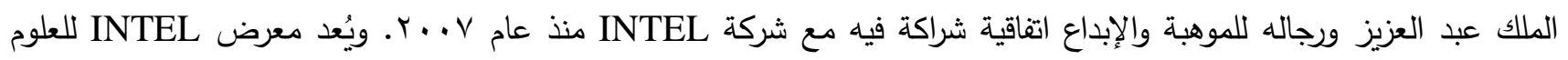

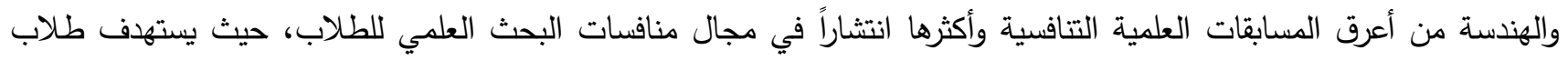

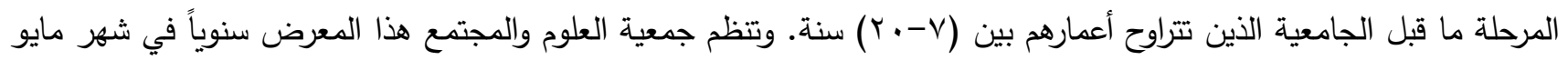

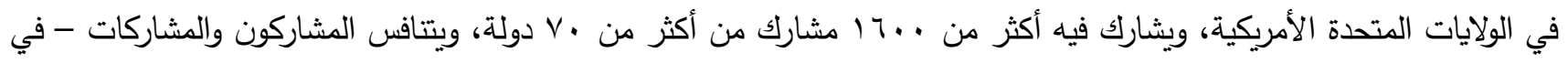

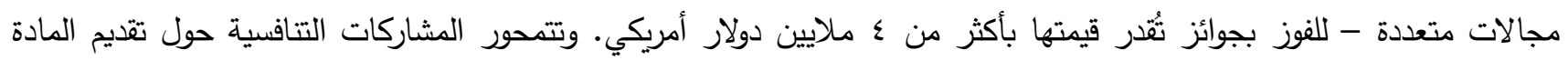

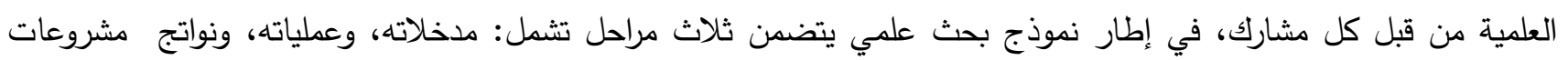
بحثية نفذها الطلاب (مركز الملك عبد العزيز ورجاله للموهبة والإبداع، 7 أ. ب).

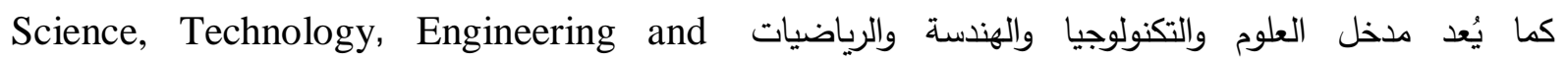
Mathematics (STEM) المعرفة العلمية، والتقنية، والهندسية، والرياضية، سعياً للتصدي إلى ضعف مخرجات التدريس المنفرد للمجالات الأربعة لتجقيق مهارات القرن الحادي والعشرين (William \& Dugger, 2013). ويتسق ذلك مع توصيات مؤتمر القدة للابتكار في التعليم

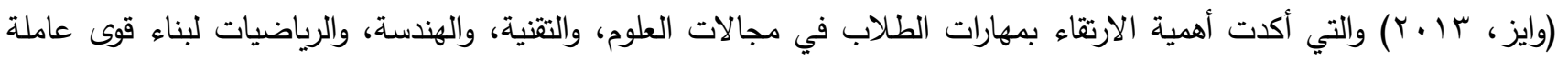

وعقدت كلية التربية في جامعة الملك سعود مؤتمراً حول مدخل STEM عام 10 ـ ب م كان يستهدف تحقيق التكامل بين فروع المعرفة العمية والتقنية والرياضيات، حيث أجريت دراسات عربية ووطنية للتحقق من فاعلية تصميم مناهج العلوم وفق مدخل مون

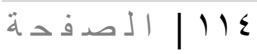


في تحقيق بعض الأهداف المعرفية والمهارية لاى الطلاب الموهوبين، ومنها دراسة الخبتي (NTEM دراسة فاعلية برنامج إثرائي مقترح قائم على مدخل STEM والتربية من أجل التنمية المستدامة في تتمية مهارات حل المشكلات

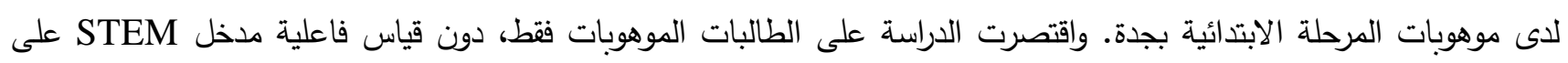

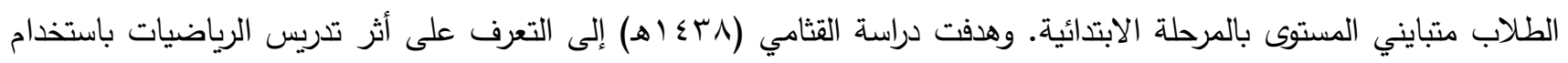

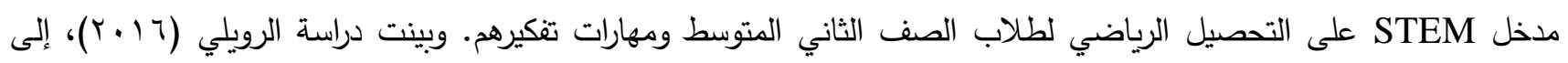
إيلاء التعلم باستخدام مهارات البحث المستقل عناية واهتماهاً أكثر ، والعمل على تعميم ذلك في الميدان التربوي، وتوفير البيئة والمواد

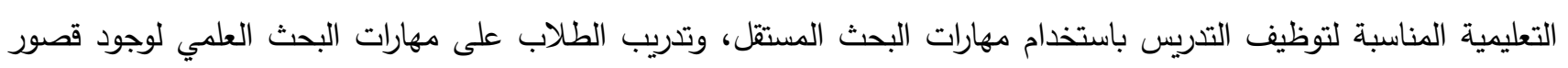
في امتلاك الطلاب لهذه المهارات، وتدريب المعلمين في الميدان على خطوات التدريس باستخدام مهارات البحث العلمي. كذلك دالك

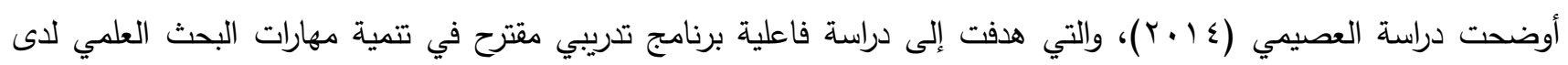

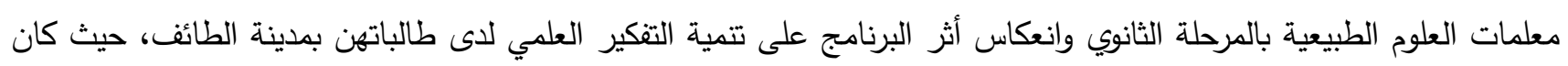

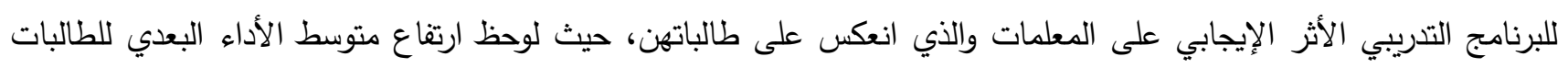

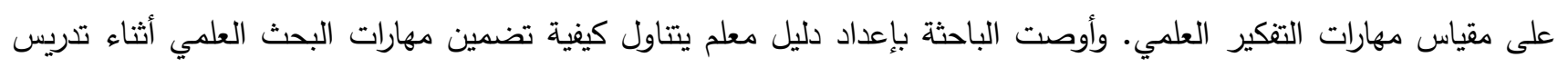
العلوم المختلفة بالمرحلة الثانوية دون التطرق للمرحلة الابتدائية. كما أجريت عدة دراسات في مجال تعليم STEM والتئي

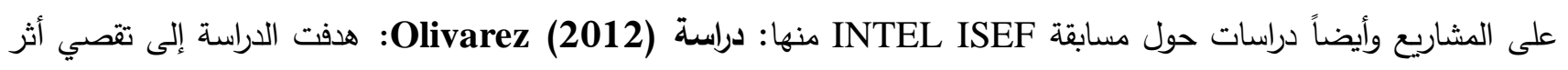
برنامج قائم على تعليم STEM في التحصيل الدراسي في العلوم والرياضيات والقراءة للصف الثاني متوسط في جنوب تكساس دراس

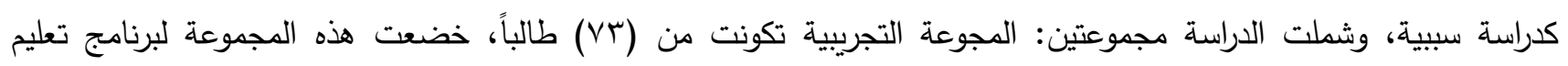

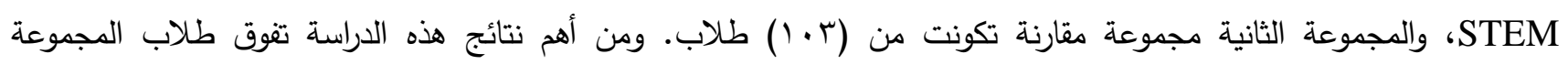
التجربية الخاضعة لتعليم STEM على المجموعة المقارنة، حيث كان المعلمون في تدريس تعليم STEM يستخدمون طرائق تدريسية حديثة، مثل: التدريب العملي، والتعلم المبني على المشروع العلمي، مما كان له أثر ايجابي في التحصيل الدراسي للعلوم

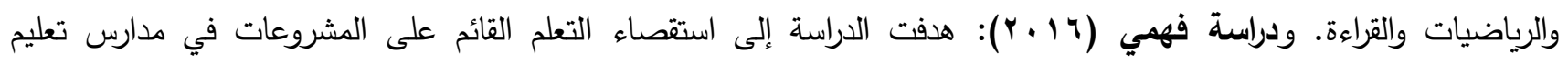
للبنين بالسادس من أكتوبر، وتُعتبر هذه المدرسة من أوائل مدارس المتفوقين في جمهورية مصر • وكان هذا الاستقصاء

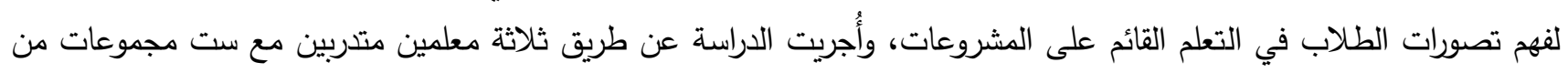

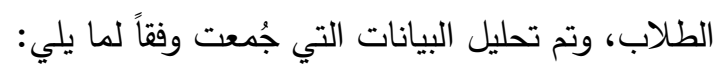

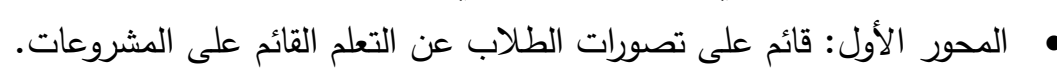

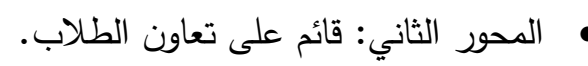

وأشارت نتائج الدراسة أن الطلاب قادرون على التعبير عن تصورات تتسم بالوضوح، وأيضاً أن الطلاب يعتقدون أن تطبيق التعلم

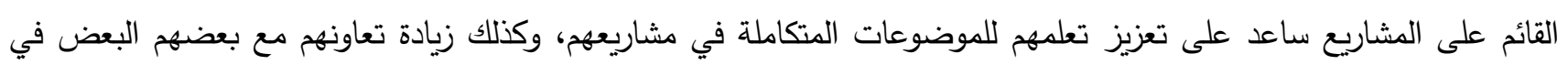

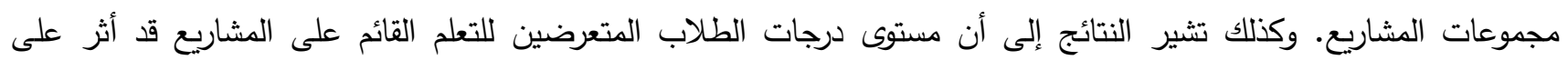

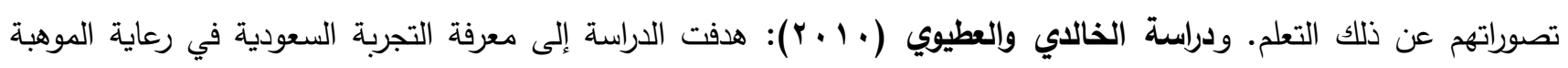

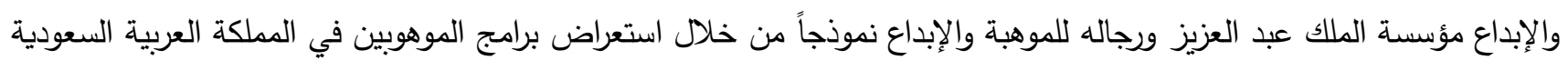

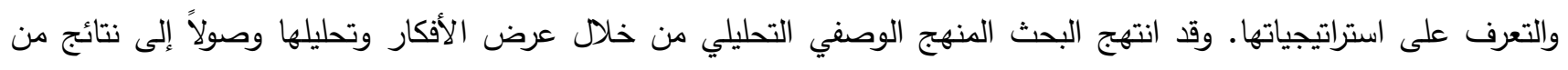
خلال مبحث مشروعات رعاية الموهوبين بالمملكة العربية السعودية وتجربة مؤسسة الملك عبد العزيز ورجاله للموهبة والإبداع.

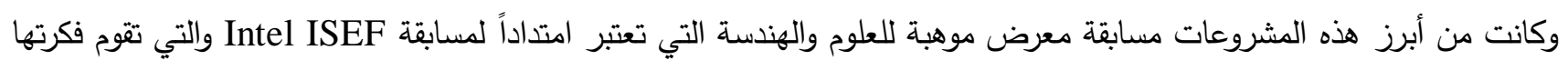
على تقديم بحث علمي في مجالات العلوم والهندسة باستخدام لوحات عرض لمشاريع الأبحاث العلمية للطلاب والطالبات، وهي

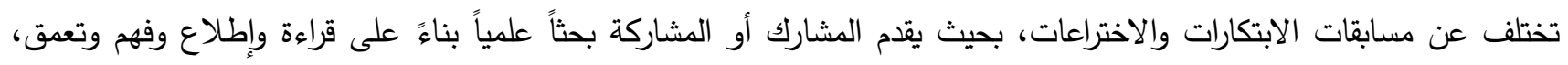
وذلك لوضع فرضيات للبحث العلمي واختبارها بالدراسة النظرية أو التجربة العملية. وتتيح مؤسسة الملك عبد العزيز للموهبة والإبداع 
"موهبة" للفائزين فرصة المشاركة في معرض إنتل الدولي للعلوم والهندسة ISEF والمسابقات الدولية وذلك بحسب ما تراه. واستتتج الباحث أن معرض العلوم والهندسة يسلط الضوء على مراحل البحث بصورة أكبر كما يهتم بالناتج المنطقي من هذه الدراسات والإحصاءات وفق تسلسل علمي مقنع ومفهوم يتوصل إليه بعد مراعاة جميع المتغيرات، ويعرض عناصر البحث الرئيسية على لوحة عرض بمواصفات ومقاسات محددة. وقدمت الباحثتان بعض التوصيات أبرزها: تعميم تجربة مؤسسة الملك عبد العزيز ورجاله في المنطقة العربية. مثكلة الاراسة:

في ضوء ما تقدم، فإن ثمة تساؤلات يمكن إثارتها حول المستقبل المأمول لتعليم مناهج العلوم في المملكة العربية السعودية، لكي تفي مناهجها في المرحلة الابتدائية بالطموحات الوطنية الخاصة بإكساب الطلاب مهارات البحث العلمي، حيث إنها تتصدر مهارات القرن الحادي والعشرين المستهدف تتميتها لدى الطلاب. ومن ثم، برز تساؤل حول مدى إمكانية توظيف مدخل

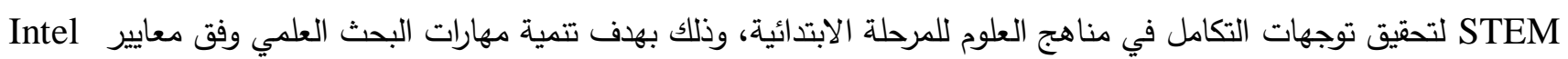
ISEF لدى طلاب مدارس التعليم العام في جدة. وهذا ما دفع الباحث إلى إجراء دراسة استطلاعية، لاستقصاء آراء مشرفي العلوم، والمعلمين، وخبراء المناهج، حول مدى

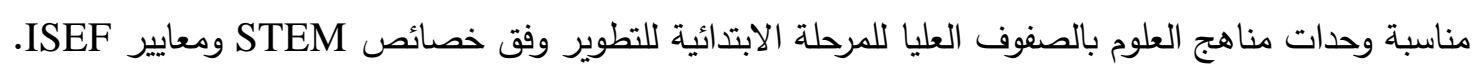
ومرت الدراسة الاستطلاعية بالإجراءات التالية:

أ- مراجعة الأدبيات التربوية: لتحديد مدلولات العناصر التالية:

مدخل STEM: هو اختصار لأربع كلمات، هي: العلوم، والتقنية، والهندسة، والرياضيات. ويسعى مدخل STEM إلى

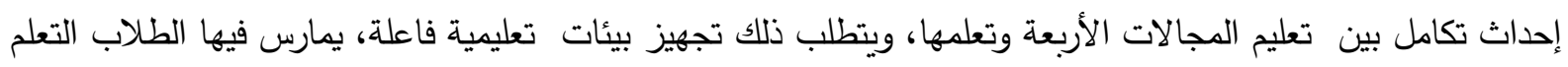
النشط في ورش العمل والمشاريع التعليمية البحثية، التي يشعر خلالها الطلاب بمتعة التعلم التي تدفعهم إلى الوصدول

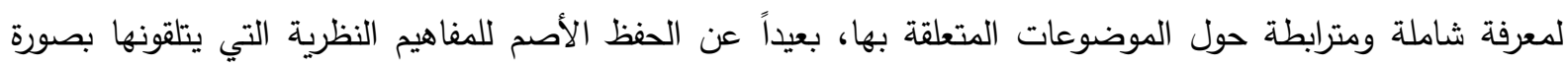
تقليدية في الفصول الدراسية (McComa, 2014).

خصائص STEM:

تتلخص خصائص STEM بإيجاز فيما يلي (المحيسن وخجا، بسـ (هـ): أ. فهم المفاهيم العلمية في تكاملها مع تطبيقاتها التكنولوجية. ب. اكتساب مهارات التفكير العلمي، والابتكاري، والفراغي. ج. اكتساب مهارات البحث، والتحري، وحل المشكلات، واتخاذ القرار . د. اكتساب مهارات الرياضيات الأساسية، وحل المشكلات الرياضية، وحلئ. هـ. معرفة المفاهيم الأساسية لعلم التصميم الهندسي. و. تتمية قدرات أداء الأنشطة ذات الصلة بالتطبيقات الهندسية.

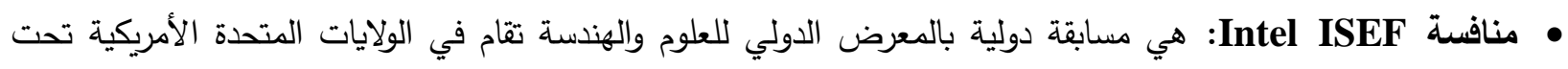

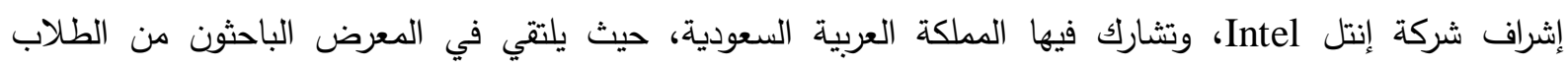
والطالبات في المرحلتين المتوسطة والثانوية (صف V - Y Y I) ، قادمين من دول متتوعة، وذلك بعد ترشيحهم من قبل

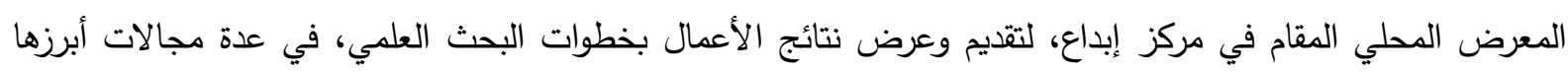

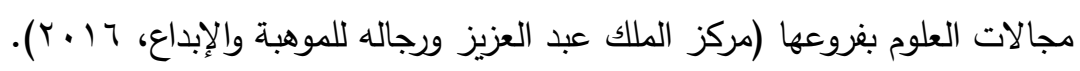

• أساليب البحث العلمي وفق معايير مسابقة Intel ISEF:

تشمل الأساليب الرئيسة للبحث وفق معايير (الأولمبياد الوطني للإبداع العلمي، 1 الـ ب) 
أ. تحديد المشكلة أو الهدف: وهي مشكلة مستقاة من المحيط والبيئة المحلية، وتصاغ على شكل سؤال أو هدف يحاول

الطالب الوصول لإجابته، ووضع فرضيات لإثباتها أو نفيها.

ب. إجراءات البحث: وهي الخطوات المتبعة في عملية البحث بمراحله المختلفة لإثبات الفرضية.

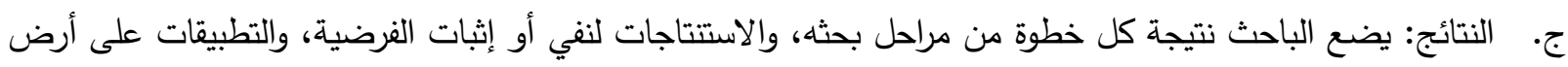

الواقع، ومدى الفائدة منها.

ب - مراجعة مقررات العلوم للصفوف الثلاثة العليا للمرحلة الابتدائية

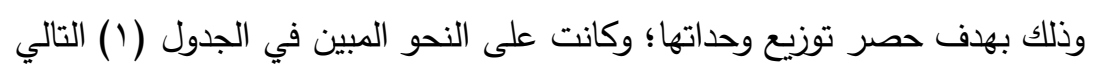

الجدول (1): الوحدات الدراسية لمناهج العلوم للصفوف الثلاثة العليا في المرحلة الابتدائية

\begin{tabular}{|c|c|c|}
\hline الوحدات & الفصول الدارسية & الصفوف الدارسية \\
\hline المخلوقات الحية & \multirow{3}{*}{ فصل (1) } & \multirow{6}{*}{ الصف الرابع } \\
\hline الأنظمة البيئية & & \\
\hline الأرض ومواردها & & \\
\hline الفضاء & \multirow{3}{*}{ فصل (r) } & \\
\hline 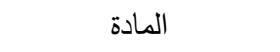 & & \\
\hline القوى والطاقة & & \\
\hline تتوع الحياة & \multirow{3}{*}{ فصل (') } & \multirow{6}{*}{ الصف الخامس } \\
\hline الأنظمة البيئية & & \\
\hline الأرض ومواردها & & \\
\hline الطقس & \multirow{3}{*}{ فصل (ץ) } & \\
\hline 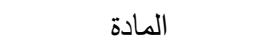 & & \\
\hline القوى والطاقة & & \\
\hline ت توع الحياة & \multirow{3}{*}{ فصل (') } & \multirow{6}{*}{ الصف السادس } \\
\hline عمليات الحياة & & \\
\hline الأنظمة البيئية ومواردها & & \\
\hline الفضاء & \multirow{3}{*}{ فصل (r) } & \\
\hline المادة & & \\
\hline القوى والطاقة & & \\
\hline
\end{tabular}

ج- إعداد الاستبانة التقييمية لآراء مشرفي العلوم، والمعلمين، وخبراء المناهج

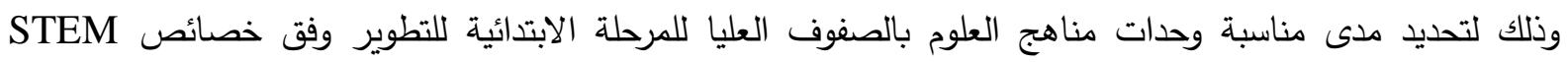
ومعايير Intel ISEF، وذلك بعد عرضها على (0) من أعضاء هيئة التدريس المتخصصين في المناهج وطرق التدريس، وتمت وهن مراعاة ملاحظاتهر.

د- تطبيق الاستبانة على (r I ) من مشرفي العلوم، والمعلمين، وخبراء المناهج. هـ- حساب الأوزان النسبية للاستجابات أظهرت النتائج أن وحدة (الأنظمة البيئية) في الصف الخامس الابتدائي بالفصل الدراسي الأول احتلت صدارة وحدات مناهج العلوم بالصفوف العليا للمرحلة الابتدائية من حيث قابليتها للتطوير وفق خصائص مدخل STEM (العلوم؛ التتنية، الهندسة، الرياضيات) بمتوسط وزني نسبي (r,^^\%)، وأن ما تثيره من مشكلات تكون قابلة للتحديد، والمعالجة، للوصول إلى نتائج وفق 
معايير Intel ISEF، وذلك بنسبة (\% \% \% ) في ضوء آراء مشرفي العلوم، والمعلمين، وخبراء المناهج.

أسئلة الدراسةة:

تحدد سؤال البحث الرئيس في: ما مدى فاعلية تدريس وحدة الأنظمة البيئية وفق مدخل STEM في تنمية مهارات البحث العلمي بمعايير نموذج Intel ISEF لدى الطلاب دارسي العلوم بالصف الخامس الابتدائي في جدة؟ وتطلبت الإجابة عنه إجابة الأسئلة الفرعية التالية:

ا ـ ما أهم الخصائص المميزة لمدخل STEM التي تلزم مراعاتها عند تطوير مناهج العلوم للمرحلة الابتدائية؟ r. ما أهم معايير نموذج Intel ISEF التي تلزم مراعاتها لتتمية مهارات البحث العلمي لدى طلاب الصفوف العليا بالمرحلة

الابتدائية؟

r. ما التصميم البنائي المقترح لاليل المعلم وأنشطة وحدة الأنظمة البيئية وفق مدخل STEM لتتمية مهارات البحث العلمي

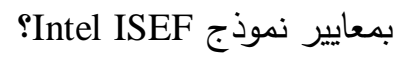
عـ ما مدى فاعلية تدريس وحدة الأنظمة البيئية وفق مدخل STEM في تتمية مهارات البحث العلمي بمعايير نموذج ISEF Intel

أهمية الدرسةة: -

$$
\text { من المتوقع أن يساهم البحث في ما يلي: }
$$

ـ ـ تعزيز مهارات البحث العلمي لدى الطلاب وفق معايير Intel ISEF عند دراستهم لوحدة الأنظمة البيئية المعدة وفق مدخل

$$
\text { Y STEM لتطوير تعليم العلوم بالمرحلة الابتدائية. }
$$

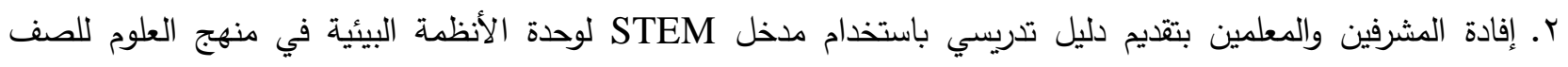

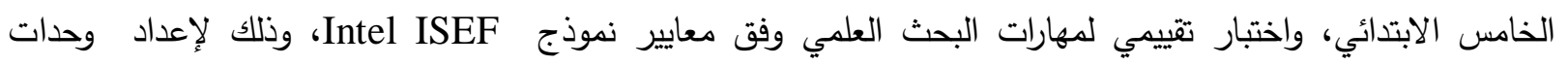
واختبارات مماثلة.

r. تزويد الباحثين والمهتمين بتطوير التعليم بتضمينات نتائج دراسة علمية تطبيقية لمدخل STEM في تتمية مهارات البحث العلمي وفق معايير نموذج Intel ISEF لطلاب المرحلة الابتدائية. ع. فتح آفاق جديدة لمجالات بحثية تطبيقية لاختبار فاعلية مدخل STEM في تصميم مناهج العلوم بمراحل تعليمية أخري، وفى مناهج تعليمية أخري على مستوى مناهج التعليم العام في المملكة العربية السعودية.

\section{مصطلحات الاراسة:}

• • مدخل STEMce, Technology, Engineering \& : (العلوم، التكنولوجيا، الهندة، الرياضيات): STEM

\section{Mathematics}

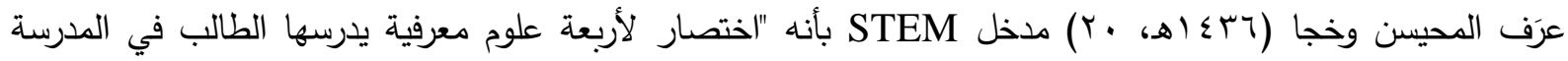

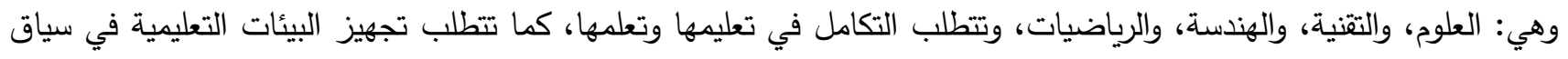
العالم الحقيقي، بحيث تساعد الطلاب على الاستمتاع في ورش العمل والمشاريع التعليمية، والتي تمكنهم من الوصول إلى المعرفة

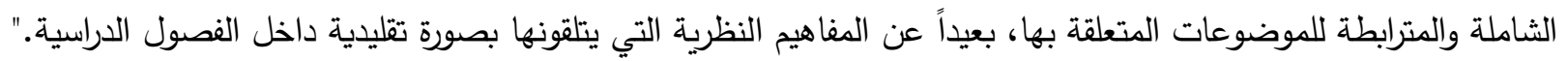

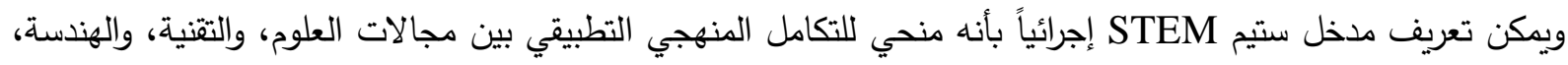
والرياضيات لتطوير وحدة الأنظمة البيئية بالصف الخامس الابتدائي، من أجل المساهمة في تتمية مهارات البحث العلمي للطلاب بلدي

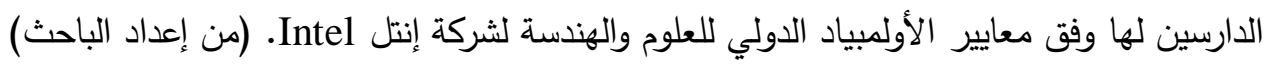


The Intel International Science and Engineering Fair معرض إنتل الدولي للعلوم والهندسة

:(Intel ISEF)

هو معرض دولي للعلوم والهندسة يلتقي فيه الباحثون من الطلاب والطالبات في المرحلتين المتوسطة والثانوية (صف V ل

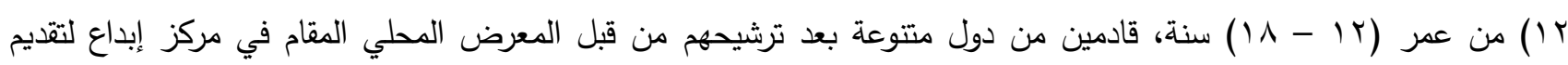

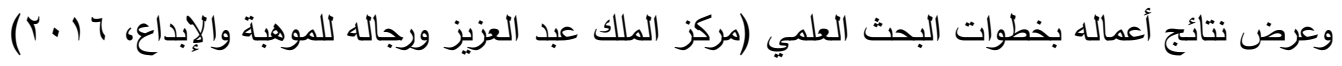

حدود الاراسة:

1. الحدود الزمنية: نفذ هذا البحث خلال الفصل الدراسي الأول للعام الدراسي وبـ أ هـ.

r. الحدود المكانية: محافظة جدة التابعة لمنطقة مكة المكرمة في المملكة العربية السعودية. r. الحدود الموضوعية: وحدة (الأنظمة البيئية) بالصف الخامس الابتدائي بكتاب الفصل الدراسي الأول.

ـ. . الحدود البشرية: عينة من طلاب الصف الخامس الابتدائي بمدارس التعليم العام بإدارة تعليم جدة.

\section{منهج الاراسة:}

تبدأ خطوات تصميم البحث باختيار المنهج العلمي المناسب، وفق طبيعة البحث، ويتم الاسترشاد في ذلك بما تمت مراجعته

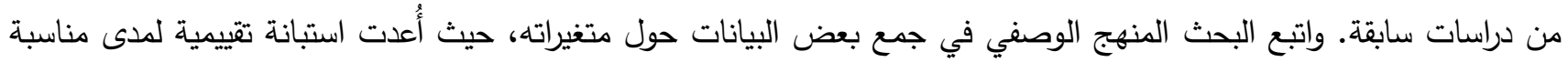

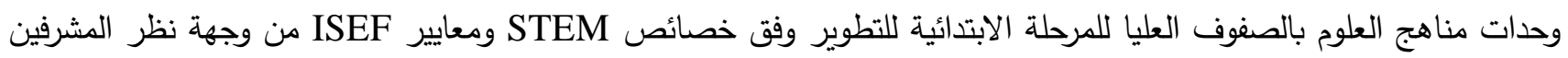
والمعلمين وخبراء المناهج. كما استُخدم المنهج التجريبي بتصميم شباء تجريبي لمجموعتين إحداهما تجريبية والأخرى ضابطة. حيث عرف مطاوع والخليفة

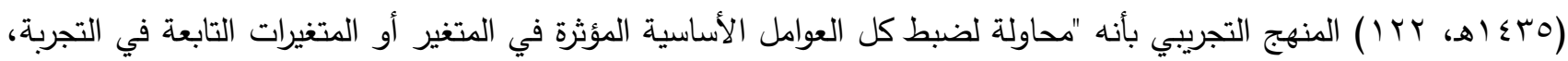
ما عدا عامل واحد يتحكم فيه الباحث ويغيره على نحو معين، بقصد قياس تأثيره على المتغير أو المتغيرات التابعة." وقد تم إتباع التهات التصميم شبه التجريبي المناسب للدراسات التربوية التي يصعب فيها تحكم الباحث في تحقيق الضبط التجريبي التام للمتغير ، ويمكن توضيح التصميم البحثي في الجدول التالي:

الجدول (؟): التصميم شبه التجريبي لمجموعتي البحث (التجريبية والضابطة)

\begin{tabular}{|c|c|c|c|c|}
\hline تطبيق بعدي & المعالجة & تطبيق قبلي & المجموعات & \multirow{3}{*}{ اختيار عشوائي لطلاب } \\
\hline \multirow{2}{*}{ 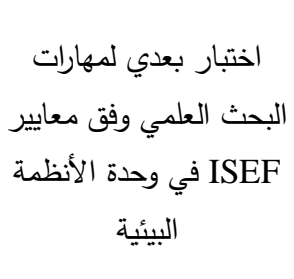 } & 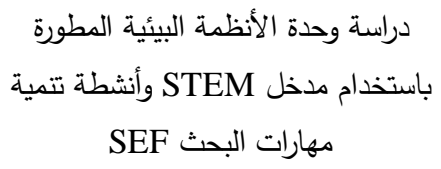 & \multirow{2}{*}{ 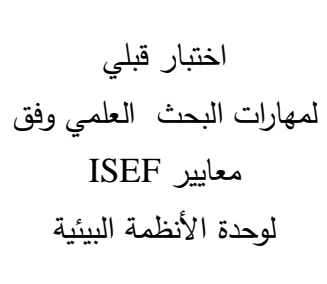 } & مجموعة تجريبية & \\
\hline & دراسة وحدة الأنظمة البيئية بالطريقة & & مجموعة ضابطة & \\
\hline
\end{tabular}

مجتمع الاراسة:

يشمل مجتمع البحث جميع طلاب الصف الخامس الابتدائي بالتعليم العام بالمدارس التابعة لإدارة تعليم جدة، خلال الفصل

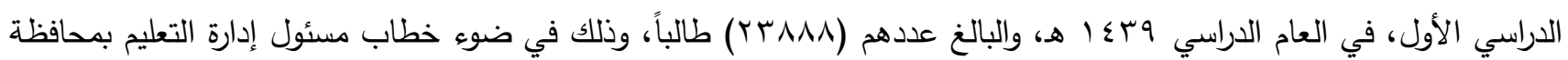

بلغت عينة البحث (•V) طالباً من طلاب المرحلة الابتدائية بمحافظة جدة، وقد قُم أفرادها إلى مجموعتين، هما: 
() المجموعة تجريبية: تألفت من (ro) طالباً من طلاب الصف الخامس بمدرسة عمير بن سعد الابتدائية، ودرست وحدة الأنظمة

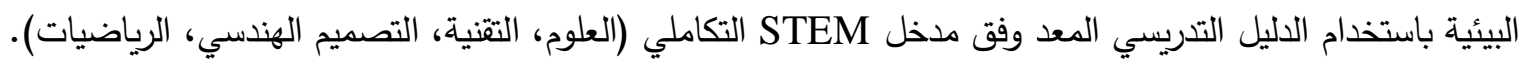

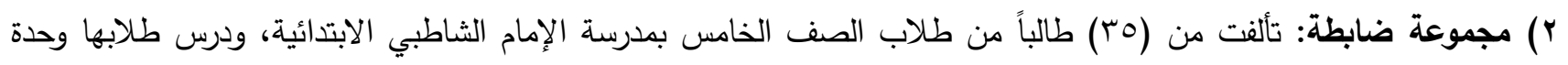
الأنظمة البيئية بالطرق التدريسية المعتاد استخدامها في تدريس العلوم. وتم اختيار عينة البحث بالطريقة العشوائية العنقودية، وذلك وفق الخطوات التالية: أ. حصر مكاتب التعليم التابعة لإدارة تعليم جدة، واختيار أحدها عشوائياً. ب. حصر مدارس المرحلة الابتدائية الموجودة في مكتب التعليم الذي تم اختياره عشوائياً، واختيار مدرستين منها بالطريقة العشوائية، إحداها للمجموعة التجريبية والأخرى للمجموعة الضابطة. ج. اختيار فصل من فصول الصف الخامس الابتدائي من كل مدرسة اختياراً عشوائياً.

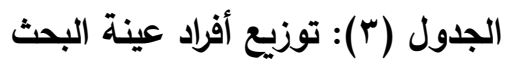

\begin{tabular}{|c|c|c|}
\hline العدد العد & المدرسة & المجموعة \\
\hline ro & ابتدائية عمير بن سعد & التجريبية \\
\hline ro & ابتدائية الإمام الثاطبي & الضابطة \\
\hline$v$. & \multicolumn{2}{|c|}{ المجموع } \\
\hline
\end{tabular}

متغيرات الاراسة:

تضمنت متغيرات البحث ما يلي: ا. المتغير المستقل: ويتمثل في طريقة التدريس باستخدام ددخل STEM (العلوم، التقنية، الهندسة، الرياضيات) في تعليم وحدة الأنظمة البيئية للمجموعة التجربيية. r. المتغير التابع: ويتمثل في تتمية مهارات البحث العلمي وفق معايير مسابقة Intel ISEF.

مواد الدراسة وأدواته: لتحقيق أهداف الدراسة والمتمثلة في التحقق من فاعلية استخدام مدخل STEM التكاملي (العلوم، التقنية، التصميم الهندسي، الرياضيات) في تتمية مهارات البحث وفق معايير ISEF في العينة التجريبية للدراسة تم استخدام أدوات الدراسة التالية:

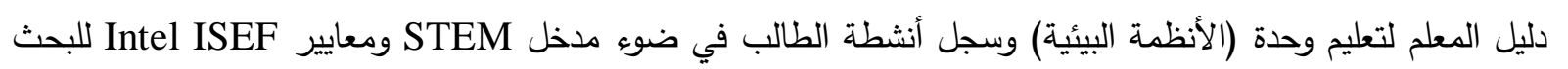
العلمي (إعداد الباحث). اختبار مهارات البحث العلمي وفق معايير مسابقة Intel ISEF (إعداد الباحث).

دليل المعلم وسجل الأنشطة: يقدم دليل المعلم وسجل الأنشطة التوجيهات لكيفية تطبيق وحدة الأنظمة البيئية لطلاب الصف الخامس باستخدام مدخل Intel ISEF للبحث العلمي، وشمل ذلك ما يلي: التكاملي، ومعايير أ. أهداف الدليل

تتمثل أهداف دليل المعلم لوحدة الأنظمة البيئية وفقاً لمدخل STEM التكاملي فيما يلي: ا. التعريف بالجانب التطبيقي للدراسة، والتي تسعى إلى معرفة" فاعلية تدريس العلوم بمدخل STEM في تتمية مهارات a 
البحث بمعايير Intel ISEF لدى طلاب المرحلة الابتدائية.

r. تصميم نماذج لتحقيق أهداف الوحدة في ضوء تعليم STEM، شاملة الطرق والاستراتيجيات والأساليب، والوسائل التعليمية،

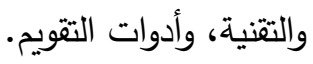

r. إبراز التكامل بين العلوم، والتتنية، والهندسة، والرياضيات، ودور كل تخصص في خدمة الآخر . ع. زيادة الدافعية لدى الطلاب نحو تعلم منهج العلوم المطور من خلال مجموعة الأنشطة المتنوعة القائمة على تعليم

.STEM

ه. تتمية مهارات البحث العلمي من خلال تدريب الطلاب على العثر على إيجاد مشكلات بحثية، وتوظيف خبراتهم في حلها

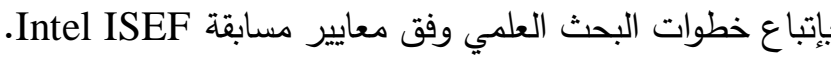

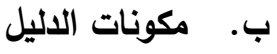
اشتمل الدليل في صورته الأولية على العناصر التالية:

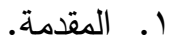

r. نبذة تعريفية عن تعليم STEM.

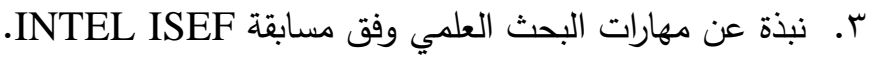
ع. توجيهات عامة للمعلم.

0. الموضوعات والمفاهيم المتضمنة في الوحدة. 7. الأهداف التعليمية للوحدة. V. الخطة الزمنية لتنفيذ الوحدة.

^. خطة دروس الوحدة في ضوء تعليم STEM. 9 9. الأنشطة المصاحبة لموضوعات الوحدة.

• ( ـقائمة بالمراجع التي يمكن أن يستقيد منها المعلم في تدريس الوحدة باستخدام مدخل تعليم STEM.

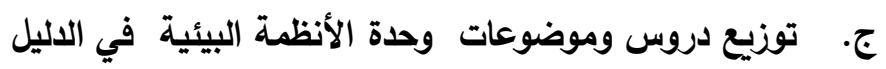

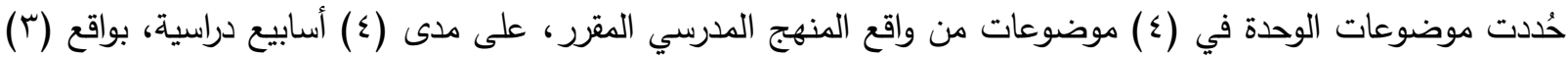

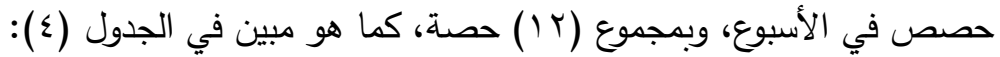
الجدول (؛): توزيع دروس الوحدة وموضوعاتها

\begin{tabular}{|c|c|c|}
\hline عدد الحصص & عنوان الموضوع & الدرس \\
\hline$r$ & العلاقات في الأنظمة البيئية & الدرس الأول \\
\hline r & التكيف والبقاء & الدرس الثاني \\
\hline r & الدورات في الأنظمة البيئية & الدرس الثالث \\
\hline r & التغيرات في الأنظمة البيئية & الدرس الرابع \\
\hline ir & \multicolumn{2}{|c|}{ المجموع - ال } \\
\hline
\end{tabular}

وبعد إعداد دليل المعلم وأنشطته، تم عرضها على مجموعة من المتخصصين في المناهج وطرق تدريس العلوم ومشرفي ومعلمي العلوم، وذلك لإبداء آراءهم حول النقاط التالية: • • مستوى الدقة العمية واللغوية.

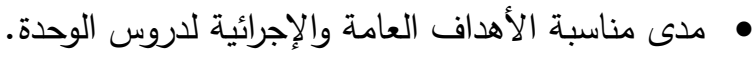

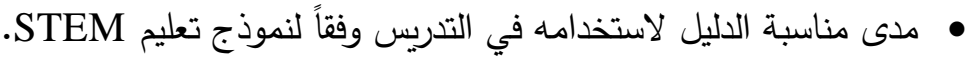
• مدى مناسبة الأدوات المقترحة لتنفيذ الأنشطة المصاحبة لمحتوى الدليل. 
• • مدى مناسبة أساليب التقويم الواردة بالدليل لتقويم أهداف الوحدة.

واقترح المحكمون بعض التعديلات منها:

1. ـ تصويب بعض الأخطاء الطباعية.

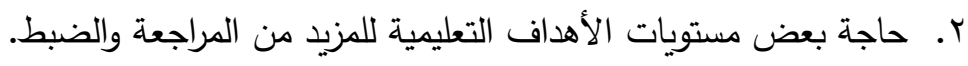

r. المزيد من الربط بين الأنشطة وفق تعليم STEM ومهارات البحث في لوحة العرض مسابقة Intel ISEF. وبعد إجراء التعديلات المقترحة من المحكمين لدليل المعلم، أصبح في صورته النهائية الصالحة للتطبيق على عينة البحث. وروعيت ملاحظات المحكمين حول دليل المعلم وأنشطته، ثم حُسبت نسب الاتفاق بين آراء المحكمين باستخدام معادلة كوبر ،

$$
\text { وبلغت } 90 \text { \% } 90 .
$$

كما تم صياغة محتوى وحدة (الأنظمة البيئية)، في صورة دروس، بحيث شمل كل درس مجموعة من الأنشطة، بما يتاسب مع خطوات تعليم STEM، ومع مهارات البحث وفق معايير ISEF.

اختبار مهارات البحث وفق معايير مسابقة Intel ISEF:

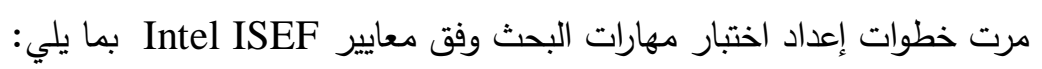

أ. تحديد المجال الموضوعي للاختبار:

شمل المجال الموضوعي للاختبار موضوعات وحدة (الأنظمة البيئية) للصف الخدار: الخامس الابتدائي.

ب. تحديا هدف الاختبار

وتحدد هدفه الرئيس في قياس مستوى مهارات الطلاب البحثية وفق معايير مسابقة Intel ISEF في مجال موضوعات

وحدة الأنظمة البيئية.

ج. تحليل محتوى وحدة الأنظمة البيئية

لتحديد مجالات الأسئلة البحثية لموضوعاتها، وتصنيف المستويات المعرفية التي يقيسها كل سؤال وفق تصنيف بلوم

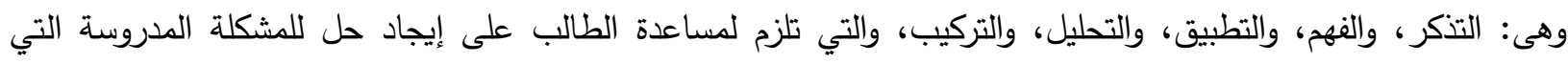

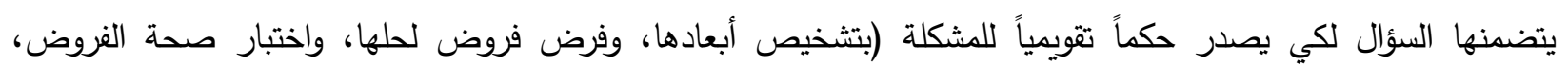
والوصول إلى أنسب الحلول).

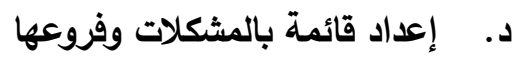

شملت القائمة الأسئلة المشكلة وفروعها، والمستويات المعرفية التي تتبعها، والرأي في انتماء السؤال للمستوى المعرفي، وذلك بعرض القائمة على محكمي البحث كما هو مبين في الجدول التالي:

الجدول (ه): قائمة بجدول مواصفات الاختبار وما يتضمنه من أسئلة مثكلة والمستويات المعرفية لها

\begin{tabular}{|c|c|c|c|c|c|c|c|c|}
\hline \multirow{3}{*}{ الملاحظات } & \multirow{2}{*}{\multicolumn{2}{|c|}{ للمستوى المعرفي }} & \multicolumn{5}{|c|}{ المستويات المعرفية } & \multirow[t]{3}{*}{ الأسئلة المشكلة وفروعها } \\
\hline & & & \multirow[t]{2}{*}{ التركيب } & \multirow[t]{2}{*}{ التحليل } & \multirow[t]{2}{*}{ التطبيق } & \multirow[t]{2}{*}{ 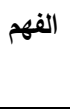 } & \multirow[t]{2}{*}{ 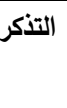 } & \\
\hline & لا ينتمي & ينتمي & & & & & & \\
\hline & & & $\sqrt{ }$ & & & & & التئوال الأول: كيف يساعداء المخلوقات الحية على \\
\hline & & & & & & & $\sqrt{ }$ & 1- المشكلة \\
\hline & & & & $\sqrt{ }$ & & & & r - الفرضيات \\
\hline & & & & & & & $\sqrt{ }$ & r- المتغيرات \\
\hline & & & & & & $\sqrt{ }$ & & צ - المراجع أو المصادر \\
\hline & & & & & & $\sqrt{ }$ & & •- المواد المستخدمة \\
\hline & & & & & $\sqrt{ }$ & & & 4- الإجراءات \\
\hline & & & & & & & $\sqrt{ }$ & v - البيانات \\
\hline
\end{tabular}




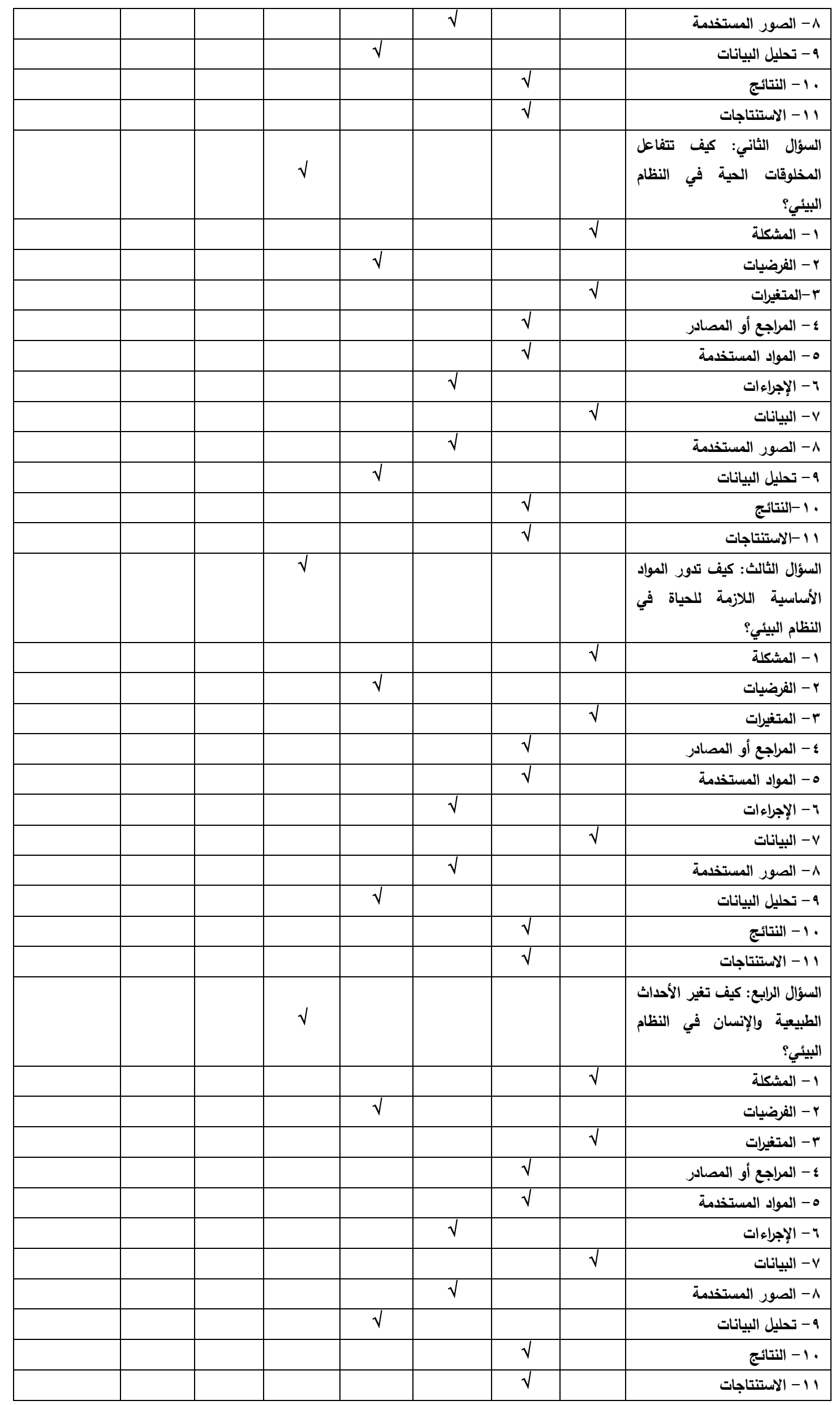




\begin{tabular}{|c|c|c|c|c|c|c|c|c|}
\hline & & & $\sqrt{ }$ & & & & & تدوير المادة؟ الخامس: كيف تتم إعادة \\
\hline & & & & & & & $\sqrt{ }$ & 1 - المشكلة \\
\hline & & & & $\sqrt{ }$ & & & & r- الفرضيات \\
\hline & & & & & & & $\sqrt{ }$ & r- المتغيرات \\
\hline & & & & & & $\sqrt{ }$ & & ؛ - المراجع أو المصادر \\
\hline & & & & & & $\sqrt{ }$ & & هـ المواد المستخدمة \\
\hline & & & & & $\sqrt{ }$ & & & 4- الإجراء ات \\
\hline & & & & & & & $\sqrt{ }$ & V - البيانات \\
\hline & & & & & $\sqrt{ }$ & & & ^- الصور المستخدمة \\
\hline & & & & $\sqrt{ }$ & & & & 9- تحليل البيانات \\
\hline & & & & & & $\sqrt{1}$ & & . 1- النتائج \\
\hline & & & & & & $\sqrt{ }$ & & 11 - الاستتتاجات \\
\hline & & & $\sqrt{ }$ & & & & & عندما تتفير الأنظمة البيئية؟ يلمال \\
\hline & & & & & & & $\sqrt{ }$ & 1- المشكلة \\
\hline & & & & $\sqrt{ }$ & & & & r- الفرضيات \\
\hline & & & & & & & $\sqrt{ }$ & r- المتغيرات \\
\hline & & & & & & $\sqrt{1}$ & & ؛ - المراجع أو المصادر \\
\hline & & & & & & $\sqrt{ }$ & & •- المواد المستخدمة \\
\hline & & & & & $\sqrt{ }$ & & & 4- الإجراءات \\
\hline & & & & & & & $\sqrt{1}$ & V - البيانات \\
\hline & & & & & $\sqrt{ }$ & & & 1-الصور المستخدمة \\
\hline & & & & $\sqrt{ }$ & & & & 9- تحليل البيانات \\
\hline & & & & & & $\sqrt{ }$ & & . 1- النتائج \\
\hline & & & & & & $\sqrt{ }$ & & 11 - الاستتناجات \\
\hline & & & 1 & ir & ir & $r \varepsilon$ & 11 & المجموع \\
\hline & & & $\Lambda, r$ & $18, v$ & $14, \mathrm{~V}$ & $r \mu, r$ & ro & النسبة المئوية \% \\
\hline
\end{tabular}


تم إعداد مفردات الاختبار في صورته الأولية، واشتمل على (T) أسئلة رئيسة، وتكون كل سؤال من (1) (1) عنصراً من نمط

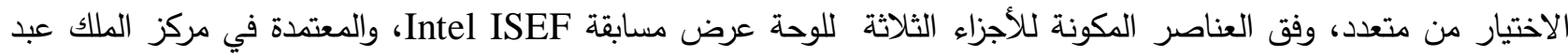

العزيز ورجاله للموهبة والإبداع (إبداع) للمشاركة في المسابقات العالمية التي تقدم مشاريع علمية. وشملت الأجزاء ما يلي:

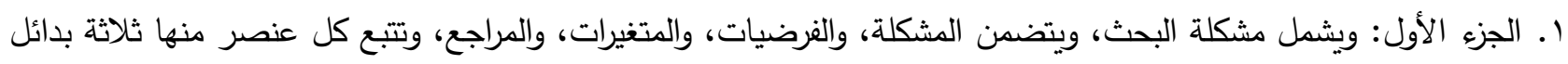

$$
\text { إجابة، توجد بينها إجابة واحدة فقط صحيحة. }
$$

r. الجزء الثاني: ويخصص لإجراءات البحث، ويشمل تحديد المواد المستخدمة، والإجراءات التتفيذية، والبيانات والصدر

المستخدمة، ونتائج تحليل البيانات. وتتبع كل عنصر منها ثلاثة بدائل إجابة، توجد بينها إجابة واحدة فقط صحيحة.

r. الجزء الثالث: ويُخصص للنتائج، ويشمل النتائج والاستتاجات التي خلص إليها البحث، وتتبع كل عنصر منها ثلاثلة بدائل

إجابة، توجد بينها إجابة واحدة فقط صحيحة.

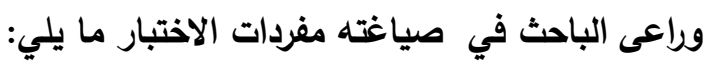

ا ب. السلامة اللغوية.

r. الثمول للمحتوى العلمي لوحدة الأنظمة البيئية.

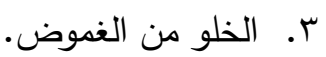

ع. مناسبة أسلوب الصياغة للمستوى العمري للطلاب.

و. تحديد تعليمات إجابة الاختبار وبيانات المستجيب

• شملت التعليمات توضيح طريقة الإجابة عن أسئلة الاختبار •

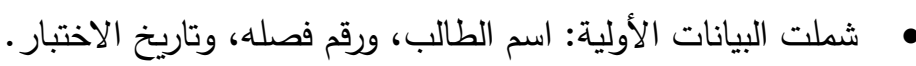

ز. وضع نظام تقدير درجات إجابة أسئلة الاختبار

تراوحت قيم الدرجات الخاصة بكل سؤال من الأسئلة الستة بين (صفر إلى الى ل1 درجة)، وبمجموع كلي (77) درجة لجميع

أسئلة الاختبار .

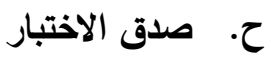

الاختبار الصادق هو الاختبار الذي يقيس ما وُضع من أجل قياسه، وقد تم حساب صدق الاختبار من خلال: الصدق

الظاهري (صدق المحكمين)، وصدق الاتساق الداخلي.

ا. صدق المحكمين:

عرض النسخة الأولية للاختبار على عدد من المحكمين المتخصصين في مناهج وطرق تدريس العلوم ومشرفي ومعلمي العلوم، وذلك للتأكد من:

• انتماء السؤال المشكل وفروعه للمستوى المعرفي الذي يقيسه.

مناسبة تحديد المشكلة.

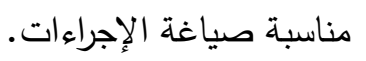

مناسبة صياغة النتائج.

وبلغ عدد المحكمين لاختبار مهارات البحث وفق معايير Intel ISEF (ع () محكماً، وقد أبدوا بعض الملاحظات التي تمت مراعاتها بشأن تساوي أطوال بعض بدائل الإجابات.

وقد أبدى المحكمون مجموعة من الملاحظات، كان من أبرزها:

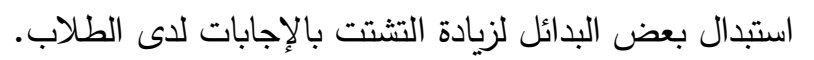

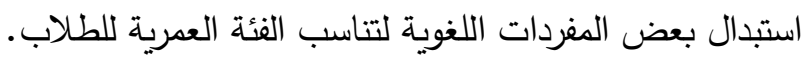


وقد روعيت ملاحظات التحكيم، وحُسبت نسبة الاتفاق بين آراء المحكمين باستخدام معادلة "كوبر"، وقد بلغت نسبتها ع,بو\%، وبذلك تم الاطمئنان على الاختبار ظاهرياً. ط. التطبيق الاستطلاعي للاختبار تم التطبيق الاستطلاعي للاختبار على عينة تكونت من (rr) طالباً (من غير طلاب عينة البحث)، وذلك للتأكد من وضوح

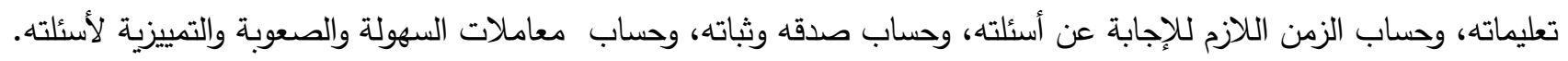
وبعد تطبيق الاختبار على العينة الاستطلاعية، تبين وضوح تعليماته، وتم حساب زمن الاختبار بتطبيق المعادلة التالية:

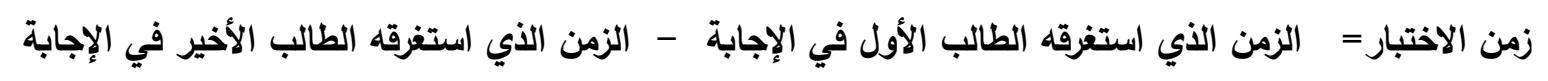
وقد كان الزمن المناسب لتأدية الاختبار هو (0؛) دقيقة. ي. انبات الاختبار

يُقصد بثبات الاختبار أن نحصل على النتائج نفسها للاختبار - أو قريب منها - إذا ما تم تطبيقه مرة أخرى على العينة نفسها، وتحت الظروف نفسها، وهو الاتساق في نتائج الاختبار عند تطبيقه من وقت لآخر • وقد قام الباحث بحساب ثبات الاختبار بالطرق التالية: التجزئة النصفية معامل ألفا كرونباخ بعد تطبيق الاختبار على العينة الاستطلاعية، وبعد تصويب الاختبار، تم حساب ثبات الاختبار من خلال معامل ألفا كرونباخ والتجزئة النصفية بعد التصحيح وفقاً لمعادلة سبيرمان براون ومعادلة جتمان. ويبين الجدول (†) التالي القيم الإحصائية: الجدول (†): قيم ثبات اختبار مهارات البحث وفق معايير مسابقة Intel ISEF في مقرر العلوم للصف الخامس الابتدائي

\begin{tabular}{|c|c|c|c|c|}
\hline \multicolumn{3}{|c|}{ معامل الثبات } & \multirow[t]{2}{*}{ عدد الفقرات الفرعية للأسئلة } & \multirow{2}{*}{ عدد الأسئلة الرئيسة } \\
\hline & بطريقة | & ألفا كرونباخ & & \\
\hline جتمان & سبيرمان براون & \multirow[t]{2}{*}{$\cdot, \mathrm{VA}$} & \multirow[t]{2}{*}{77} & \multirow[t]{2}{*}{1} \\
\hline$\cdot, v \cdot$ & $\cdot, V Y$ & & & \\
\hline
\end{tabular}

ويتضح من الجدول (†) أن معامل الثبات لاختبار مهارات البحث وفق معايير مسابقة Intel ISEF بطريقة ألفا كرونباخ بلغ

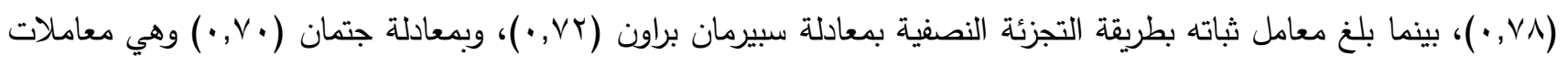

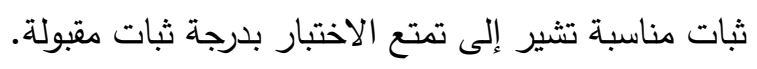
ك. صدق الاتساق الداخلي لحساب صدق الاتساق الداخلي للاختبار التحصيلي لمهارات البحث وفق معايير مسابقة INTEL ISEF في مقرر العلوم للصف الخامس الابتدائي، قام الباحث بحساب معاملات ارتباط بيرسون للعلاقة بين درجة كل بند من بنود الاختبار مع الدرجة

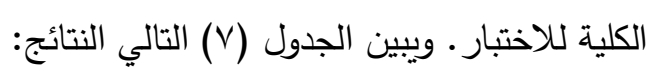
الجدول (V): معاملات الارتباط بين كل بند من بنود الاختبار التحصيلي مع الدرجة الكلية للاختبار

\begin{tabular}{|c|c|c|c|c|c|c|c|c|c|}
\hline معامل الارتباط & السؤال & معامل الارتباط & السؤال & معامل الارتباط & السؤال & معامل الارتباط & السؤال & معامل الارتباط & السؤال \\
\hline $.297 \% *$ & $0 \leq$ & $.287 \% *$ & $\leqslant 1$ & $.390 \%$ & rA & $.479 \%$ & 10 & $.311^{* * *}$ & 1 \\
\hline $.288 \div *$ & 00 & $.265 \%$ & $\varepsilon r$ & $.486 \% *$ & rq & $.262 \% *$ & 17 & $.425 \% *$ & $r$ \\
\hline $.299 * *$ & 07 & $.330 \%$ & $\varepsilon r$ & $.323^{*}$ & $r$. & $.297 \% *$ & IV & $.389 * *$ & $r$ \\
\hline $.284 * *$ & ov & $.384 * *$ & $\varepsilon \varepsilon$ & $.336^{*}$ & ו & $.371^{* * *}$ & 11 & $.306^{* * *}$ & $\varepsilon$ \\
\hline
\end{tabular}




\begin{tabular}{|c|c|c|c|c|c|c|c|c|c|}
\hline $.501 \% *$ & $0 \wedge$ & $.395^{* *}$ & $\varepsilon 0$ & $.297 *$ & Tr & $.510 \%$ & 19 & $.331 \%$ & 0 \\
\hline $.375^{* * *}$ & 09 & $.363 *$ & $\varepsilon 7$ & $.379 \%$ & זr & $.410^{* * *}$ & $r$. & $.281 \%$ & 7 \\
\hline $.320 * *$ & 7. & $.298 * *$ & $\varepsilon V$ & $.295 * *$ & $r \varepsilon$ & $.343^{* * *}$ & rI & $.258 \% *$ & V \\
\hline $.424 \% *$ & 71 & $.544 \% *$ & $\varepsilon \wedge$ & $.490 \% *$ & ro & $.322 \%$ & Kr & $.219^{*}$ & $\wedge$ \\
\hline $.286^{* * *}$ & $4 \pi$ & $.328^{* * *}$ & $\varepsilon 9$ & $.267 * *$ & 4 & $.284 * *$ & r & $.422 \% *$ & 9 \\
\hline $.435^{* *}$ & זי & $.501 \% *$ & 0. & $.303^{* * *}$ & $r v$ & $.400 \% *$ & $r \leq$ & $.345^{* * *}$ & 1. \\
\hline $.352 \%$ & $7 \varepsilon$ & $.431 \% *$ & 01 & $.412 *$ & ru & $.554 \% *$ & ro & $.436 \% *$ & 11 \\
\hline $.377 * *$ & 70 & $.405^{* * *}$ & or & $.290 \%$ & $r q$ & $.357 \%$ & rT & $.309^{* * *}$ & Ir \\
\hline \multirow[t]{2}{*}{$.344 * *$} & 47 & $.320 \%$ & or & $.402 * *$ & $\varepsilon$ & $.499 *$ & $r V$ & $.283^{*}$ & Ir \\
\hline & & & & & & & & $.486 \%$ & $1 \varepsilon$ \\
\hline
\end{tabular}

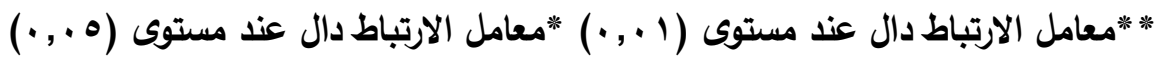

من الجدول (V) نجد أن جميع قيم معاملات الارتباط بين كل بند من بنود الاختبار التحصيلي مع الدرجة الكلية للاختبار

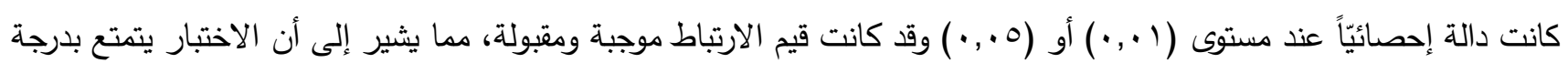
مقبولة من الاتساق والتماسك الداخلي. كما أُجريت المقارنة الطرفية للاختبار لمعرفة قدرته على التمييز بين طرفي القدرة التي يقيسها، حيث تم أخذ (0؟\%م) من الدرجات المرتفعة لتمثل مجموعة الإرباعي الأعلى، و(Y0\%) من الدرجات المنخفضة لتمثل مجموعة الإرباعي الأدنى، وتمت المقارنة بين متوسطي الإرباعيين(الأعلى والأدنى) باستخدام اختبار (ت) للمقارنة بين المتوسطات، ورُصدت النتائج في الجدول (^)

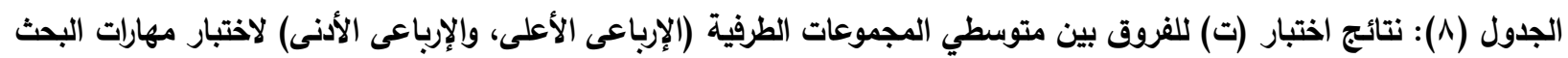

\begin{tabular}{|c|c|c|c|c|c|c|c|}
\hline الدلاية & قيمة (ت) & الدرجة & الانحراف & المتوسط & العينة & الإرباعيات & المتغير \\
\hline \multirow{2}{*}{ دال عند } & \multirow[t]{2}{*}{$1 \varepsilon, r r$} & \multirow[t]{2}{*}{11} & 1.98 & 23.0 & 6 & الإرباعي الأعلى & \multirow[t]{2}{*}{ ختبار مهارات البحث } \\
\hline & & & 2.54 & 34.0 & 7 & الإرباعي الأدنى & \\
\hline
\end{tabular}

ويتضح من الجدول (^) وجود فروق ذات دلالة إحصائية عند مستوى 0.01 بين متوسطات مجموعة الإرباعي الأعلى الإنى ومتوسطات مجموعة الإرباعي الأدنى على الاختبار التحصيلي لمهارات البحث وفق معايير مسابقة Intel ISEF في مقرر العلوم

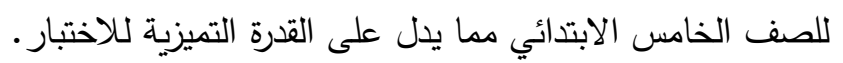
ل. ل معاملات السهولة والصعوبة والتمييز بعد تصويب درجات الطلاب (العينة الاستطلاعية) في اختبار مهارات البحث، تم تحليل تلك الدرجات لحساب معامل الصعوبة والسهولة ومعامل التمييز بين الطلاب في هذا الاختبار كالتالي: درجات الطينه

$$
\begin{aligned}
& \text { معامل , السهولة = ع عدد الإجابات الصحيحة }=
\end{aligned}
$$

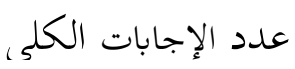

وتم حساب معامل الصعوبة من خلال المعادلة الآتية:

$$
\text { معام| , الصعهوبة = عدد الإجابات الخطأ }
$$

وبعد إجراء الحساب الرياضي من خلال المعادلتين السابقتين، تبين أن معاملات السهولة انحصرت بين (דب, • - 79, • )

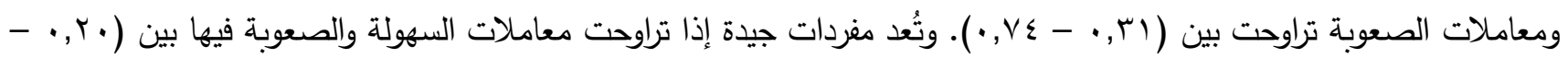




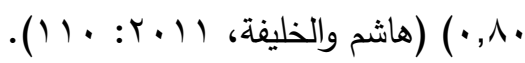

أما معامل التمييز فيُعَصد به أن تكون للاختبار القدرة على إبراز الفروق بين المفحوصين من حيث تفوقهم في تحصيل المادة

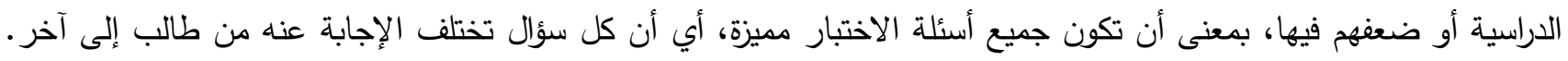
وتم حساب معامل التمييز باستخدام المعادلة الآتية:

\section{معامل التمييز= معامل السهولة × معامل الصعوبة.}

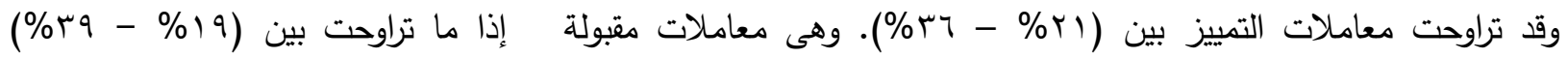

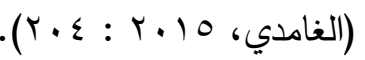

وبذلك تم التحقق من توافر الشروط السيكومترية فى الاختبار، وأصبح في صورته النهائية الصالحة للتطبيق على عينة البحث، حيث اشتمل على (T) أسئلة رئيسة، تتبع كل سؤال منها (1) (1) فقرة من نوع الاختيار من متعدد ثلاثي البدائل.

خطوات تطبيق الدراسة ميدانياً: للإجابة عن أسئلة البحث، والتحقق من مدى صحة فروضا: لإنه، تم اتباع المراحل الإجرائية التتفيذية لخطوات البحث على النحو التالي: ا. مراجعة الأدبيات السابقة التي تتاولت متغيرات البحث (مدخل STEM البنائي التكاملي، مهارات البحث وفق معايير مسابقة .(Intel ISEF r. إعداد اختبار تقييمي استطلاعي للمهارات البحثية الواردة في وحدة الأنظمة البيئية بمنهج العلوم للصف الخامس الابتدائي، والتحقق من استيفائه معايير الصدق والثبات.

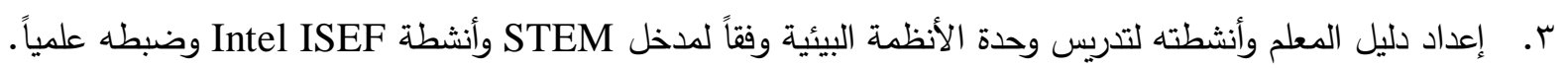
ء. أخذ الموافقات الرسمية لبدء تتفيذ الدراسة الميدانية، بالحصول على خطاب سعادة عميد كلية التربية بجامعة جدة والموجه إلى ولى

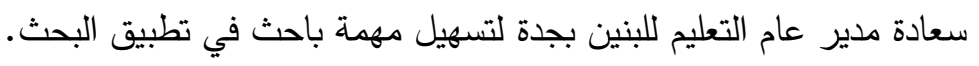
ه. تم تحديد المجموعتين التجريبية والضابطة للعينة بالطريقة العشوائية العنقودية، حيث بلغ عدد كل مجموعة (ب) طالبين طالباً من طلاب الصف الخامس الابتدائي بمدينة جدة. 7. التطبيق القبلي لاختبار مهارات البحث وفق معايير ISEF على طلاب المجموعتين الضابطة والتجريبية وذلك بتاريخ

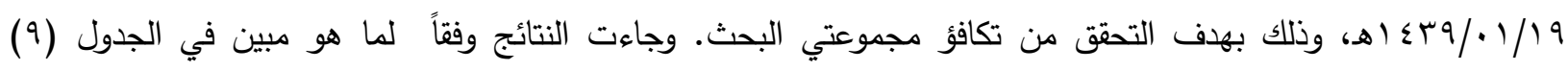
التالي:

الجدول (9): نتائج اختبار (ت) لدلالة الفروق بين متوسطات درجات المجموعتين التجريبية والضابطة في التطبيق القبلي لاختبار مهارات البحث وفق معايير مسابقة Intel ISEF

\begin{tabular}{|c|c|c|c|c|c|c|c|}
\hline $\begin{array}{c}\text { (الدلالة } \\
(\cdot, \cdot, 0)\end{array}$ & درجة المعنوية & قيمة (ت) & درجة الحرية & الانحراف & المتوسط & حجم العينة & المجموعات \\
\hline \multirow[t]{2}{*}{ غير دالة } & \multirow[t]{2}{*}{., 179} & \multirow[t]{2}{*}{$1, r \wedge 9$} & \multirow[t]{2}{*}{71} & 4.15 & 25.6 & ro & الضابطة قبلي \\
\hline & & & & 7.15 & 27.5 & ro & التجريبية قبلي \\
\hline
\end{tabular}

تثير نتائج اختبار (ت) في الجدول (9) السابق إلى عدم وجود فروق ذات دلالة إحصائية بين متوسطات درجات طلاب

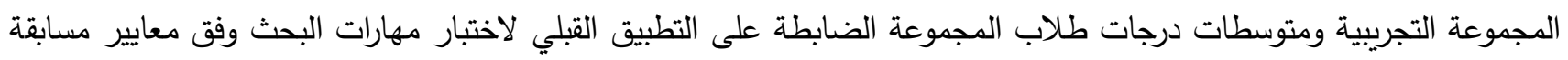
في مقرر العلوم للصف الخامس الابتدائي، حيث بلغ متوسط (T, Intel ISEF 


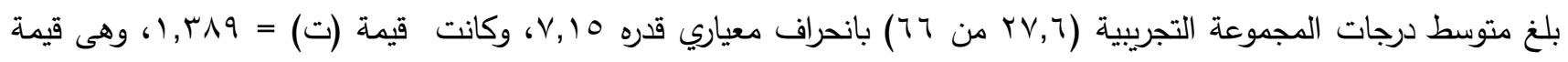
غير دالة إحصائياً عند مستوى معنوية ه. . . • تشير إلى تكافؤ مجموعتي البحث.

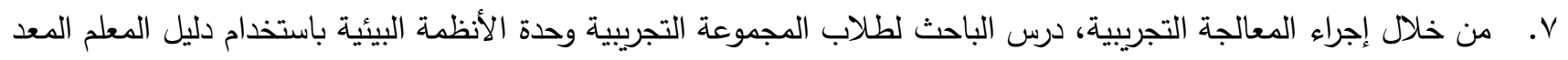
لتدريسها بمدخل STEM وفق معايير مسابقة Intel ISEF، بينما يدرس طلاب المجموعة الضابطة الوحدة بالطرق المعتادة

$$
\text { في المدارس. واستغرق ذلك (ع) أسابيع. }
$$

وقد تبين تفاعل طلاب المجموعة التجريبية مع الأنشطة التعليمية للوحدة المعدة وفق مدخل STEM، وذلك من خلال مجموعات العمل النقاشية للمشكلات التي أُثيرت في الموضوعات الستة لفئ بمجال الوحدة، والإجراءات المتبعة في حلها، واختيار أنسب الحلول التي توصلوا إليها. ^. عقب انتهاء طلاب المجموعتين من دراسة وحدة الأنظمة البيئية، تم التطبيق البعدي لاختبار مهارات البحث وفق معايير ISEF على طلاب المجموعتين التجريبية والضابطة. 9 . تم رصد النتائج وأُجريت المعالجة الاحصائية بالأساليب البارامترية المناسبة (T. Test) للإجابة عن أسئلة البحث، والتحقق

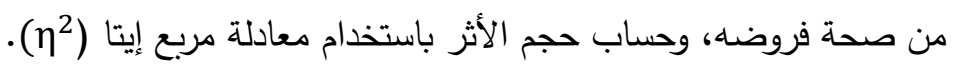
• ا ـ تقديم التوصيات والمقترحات في ضوء النتائج التي تم التوصل إليها.

الأساليب الإحصائية:

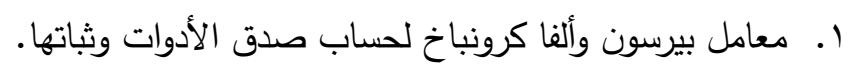

r. تم حساب المتوسطات الحسابية والانحرافات المعيارية واختبار "ت" (T. Test) للتعرف على دلالة الفروق بين المجموعتين

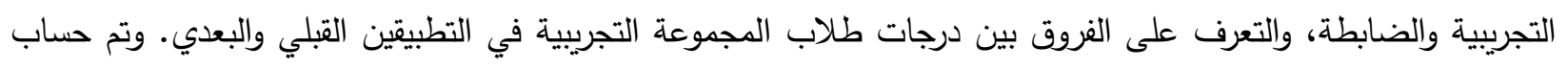
قيمة مربع إيتا (خ2) لمعرفة حجم الأثر الذي يحدثه المتغير المستقل (مدخل STEM) في المتغير التابع (مهارات البحث العلمي وفق معايير Intel ISEF r. اختبار (Kruskal-Wallis) لحساب دلالة الفروق في المهارات البحثية لدى طلاب المجموعة التجريبية التي تم تصنيفهم في مئي ثلاثة مستويات مهارية (مرتفع، متوسط، منخفض).

\section{نتائج الدراسة (عرضها - مناقشتها - تفسيرها):}

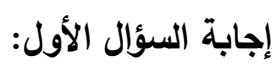

الذي نص على: ما هي أهم الخصائص المميزة لمخل STEM التي يلزم مراعاتها عند تطوير منهج العلوم للمرحلة

لتحديد أهم الخصائص المميزة لمدخل STEM التي تلزم مراعاتها عند تطوير مناهج العلوم للمرحلة الابتدائية، تمت مراجعة الأدبيات التربوية لاستخلاص الخصائص المميزة لمدخل STEM، ثم أُعدت استبانة تقييمية للتعرف على آراء مشرفي العلوم

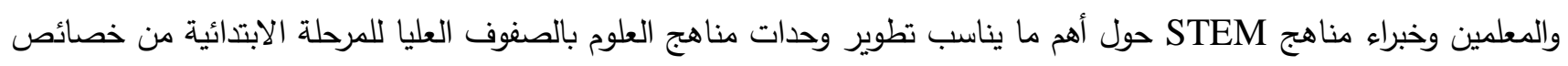
مميزة لمدخل STEM. وفى ضوء تحليل نتائج استجاباتهم تحددت أهم الخصائص التالية: 1. أ. فهم المفاهيم العلمية والرياضية والهندسية وتطبيقاتها التقنية. r. ت. تتمية مهارات التفكير العلمي، والابتكاري، والفراغي. r. إتاحة خبرات ممارسة مهارات البحث، والتحري، وحل المشكلات، واتخاذ القرار . ء. . تتمية المهارات الرياضيات الأساسية، ومهارات حل المشكلات الرياضية. 0. اكتساب المفاهيم الأساسية للتصميم الهندسي. 
7. توفير أنشطة لممارسة التطبيقات الهندسية. كما أظهرت نتائج استجاباتهم أن وحدة (الأنظمة البيئية) في الصف الخامس الابتدائي حصلت على متوسط وزني كبير بلغ (ץ, ؟^\%) من حيث إمكانية مراعاة خصائص مدخل STEM (العلوم، التقنية، الهندسة، الرياضيات) في تطويرها. إجابة السؤال الثاني:

الذي نص على: ما هي أهم معايير نموذج Intel ISEF التي تلزم مراعاتها لتنمية مهارات البحث العلمي لدى طلاب الصفوف العليا بالمرحلة الابتدائية؟ ها هي الصم

وتمت الإجابة عنه من خلال مراجعة الأدبيات التربوية لاستخلاص أهم معايير نموذج ISEF التي تلزم مراعاتها لتتمية مهارات البحث العلمي لدى طلاب الصفوف العليا بالمرحلة الابتدائية. وشمل ذلك مراجعة لوحة العرض المعتمدة بمركز الملك عبد العزيز

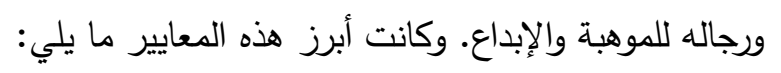

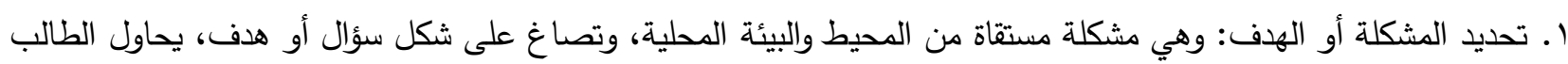

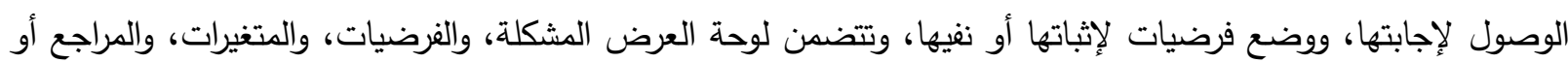

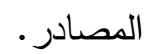
r. إجراءات البحث: وهي الخطوات المتبعة في عملية البحث بمراحله المختلفة لإثبات الفرضية، وتتضمن لوحة العرض: المواد المستخدمة، والإجراءات، والبيانات، والصور المستخدمة أو الرسوم البيانية، وتحليل البيانات.

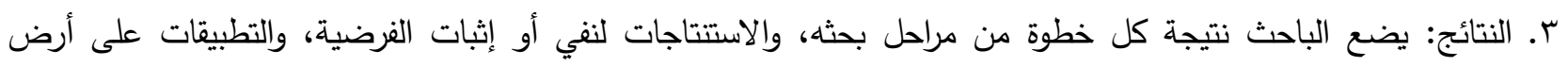
الواقع، ومدى الفائدة منها، وتتضمن لوحة العرض: لئه كل النتائج، والاستنتاجات. إجابة السؤال الثالث: الذي نص علي: ما هو التصميم البنائي المقترح لدليل المعلم وأنثطة وحدة الأنظمة البيئية وفق مدخل STEM لتنمية مهارات

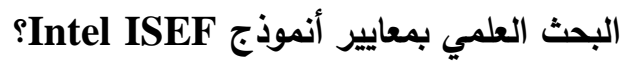
تمت الإجابة عنه بإعداد دليل لتدريس وحدة الأنظمة البيئية باستخدام ددخل STEM (كما سبق توضيح ذلك في فصل

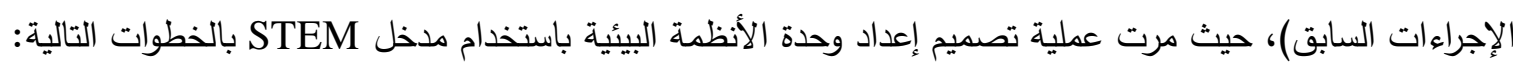

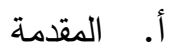

ب. نبذة تعريفية عن تعليم STEM.

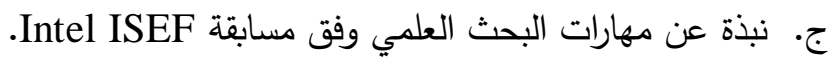
د. توجيهات عامة للمعلم. هـ الموضوعات والمفاهيم المتضمنة في الوحدة. و. الأهداف التعليمية للوحدة. ز. الخطة الزمنية لتنفيذ الوحدة

ح. خطة دروس الوحدة في ضوء تعليم STEM

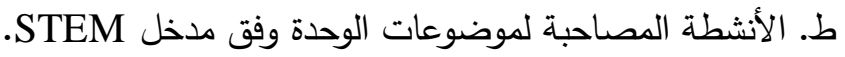
ي. قائمة بالمراجع التي يمكن أن يستئيد منها المعلم في تدريس الوحدة باستخدام مدخل تعليم وتضمن الدليل خططاً تدريسية لموضوعات الوحدة البالغ عددها (ع) موضوعات شملت العلاقات في الأنظمة البيئية، والتكيف والبقاء، والدورات في الأنظمة البيئية، والتغيرات في الأنظمة البيئية. وشمل كل موضوع أنشطة تعليمية بمدخل تعليم Sوفق معايير Intel ISEF لمهارات البحث. STEM 
إجابة السؤال الرابع:

الذي نص على: ما هي فاعلية تدريس وحدة الأنظمة البيئية وفق مدخل STEM في تنمية مهارات البحث العلمي وفق

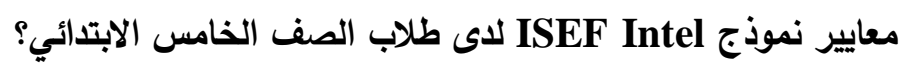
تمت الإجابة عن هذا السؤال من خلال اختبار فروض البحث، وذلك الهاب على النحو التالئي: نتائج اختبار الفرض الأول

لاختبار صحة الفرض الأول والذي ينص على أنه "لا توجد فروق ذات دلالة إحصائية عند مستوى (1) (ل0.05) بين

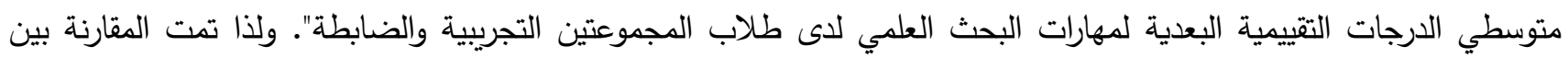
متوسطي درجات طلاب المجموعتين التجريبية والضابطة في التطبيق البعدي بحساب قيمة اختبار (ت)، ورُصدت النتائج في

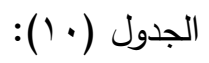

الجدول ( • (): اختبار (ت) لالالة الفروق بين متوسطي درجات طلاب المجموعتين (الضابطة والتجريبية) في التطبيق البعدي لاختبار

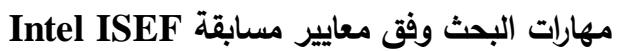

\begin{tabular}{|c|c|c|c|c|c|c|c|}
\hline الدلالة & المغنوية & قيمة (ت) & درجة الحرية & المعياري & المتوسط & حجم العينة & المجموعات \\
\hline \multirow{2}{*}{ (1 الة عند } & \multirow[t]{2}{*}{$\cdot, \ldots 1$} & \multirow[t]{2}{*}{$1 \cdot, \cdot \varepsilon$} & \multirow[t]{2}{*}{41} & 4.64 & 29.97 & 35 & الضابطة بعدي \\
\hline & & & & 13.87 & 54.8 & 35 & التجريبية بعدي \\
\hline
\end{tabular}

تشير النتائج الموضحة في الجدول (• (1) أن قيمة "ت" المحسوبة دالة إحصائيا (عند مستوى ا..,·)، ويعني ذلك وجود فروق ذات دلالة إحصائية بين متوسطي درجات طلاب المجموعتين التجريبية والضابطة في التطبيق البعدي لاختبار البحث لصالح طلاب المجموعة التجريبية. فبمقارنة المتوسطات لكل من الدموعتين نجد أن متوسط درجات الطلاب في المجموعة الضابطة في التطبيق البعدي كان

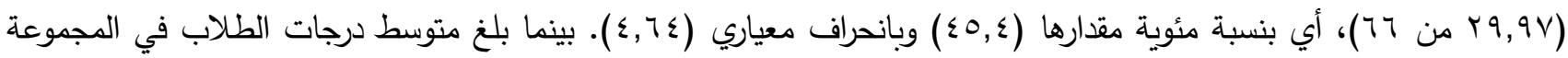

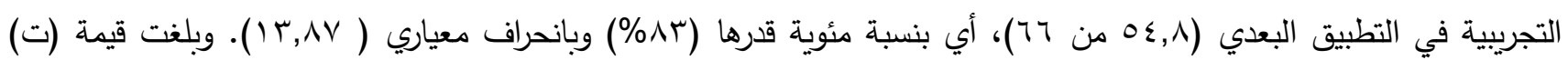
المحسوبة (ع •. • ()) وهى قيمة دالة إحصائياً عند مستوى دلالة (0. (. • ).

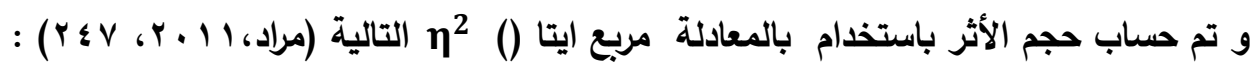
$\eta^{2}=\frac{t^{2}}{t^{2}+\left(n_{1}+n_{2}-2\right)}$

وبلغ حجم الأثر المحسوب بمعادلة مربع إيتا (Y2) (VO, · )، وهى نسبة تثير إلى حجم أثر كبير يعكس التحسن في مستويات مهارات البحث العلمي لدى طلاب الصف الخامس الابتدائي بجدة، والذي يُعزي إلى فاعلية تدريس العلوم بوحدة الأنظمة البيئية وفق مدخل ستيم STEM وفق معايير Intel ISEF.

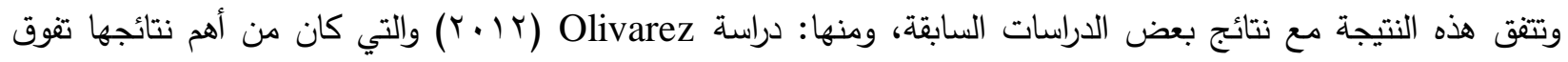
طلاب المجموعة التجريبية الخاضعة لتعليم STEM على المجموعة المقارنة في التحصيل الدراسي في العلوم والرياضيات والقراءة، حيث كان المعلمون في تدريس تعليم STEM يستخدمون طرائق تدريسية حديثة، مثل: التدريب العملي والتعلم المبني على المشروع العلمي، مما كان لله أثر إيجابي في التحصيل الدراسي للعلوم والرياضيات والقراءة. وكذلك تتقق هذه النتيجة مع نتائج دراسة التثامي ( ) (التي أثبتت وجود أثر دال إحصائياً لتدريس الرياضيات باستخدام ددخل STEM على التحصيل الدراسي ومهارات التفكير لدى طلاب الصف الثاني المتوسط، كما أظهرت نتائجها وجود فروق ذات دلالة إحصائية في التطبيق البعدي عند مستوى 
(المي0.05) فيما يخص التحصيل الدراسي لصالح المجموعة التجريبية، ووجود فروق ذات دلالة إحصائية في التطبيق البعدي عند

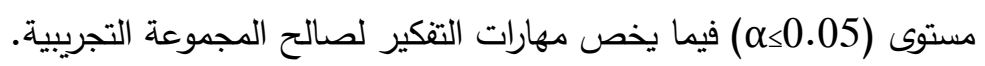
نتائج اختبار الفرض الثاني لاختبار صحة الفرض الثاني الذي نص على أنه "لا توجد فروق ذات دلالة إحصائية عند مستوى (0.05 إنم) بين متوسطات معدل

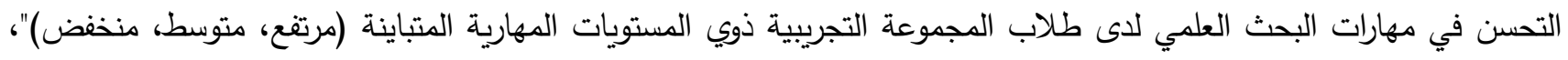

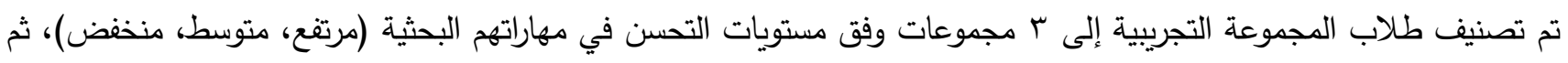

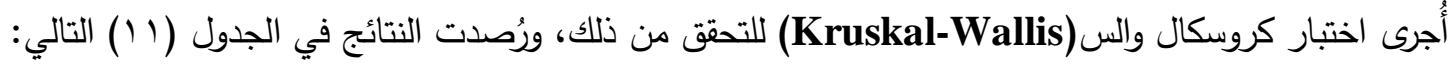
جدول(11) (1) اختبار(Kruskal-Wallis) لدلالة الفروق في المهارات البحثة لاى طلاب المجموعة التجريبية التي تم تصنيفهم في ثلاثة

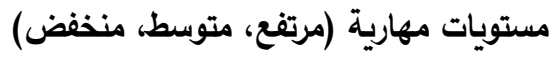

\begin{tabular}{|c|c|c|c|c|c|}
\hline $\begin{array}{c}\text { p-مستوى الدلالة } \\
\text { value }\end{array}$ & قيمة $x^{2}$ & متوسط الرتب & حجم العينة & معدلات & المتغير \\
\hline \multirow[t]{3}{*}{.538} & \multirow[t]{3}{*}{1.239} & 15.54 & 12 & مرتفع & \multirow{3}{*}{ البحث العروق في معدل التحسن في مهارات } \\
\hline & & 20.08 & 13 & متوسط & \\
\hline & & 18.25 & 10 & منخفض & \\
\hline
\end{tabular}

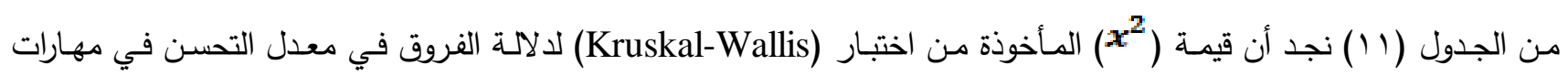
البحث العلمي لاى طلاب المجموعة (مرتفع، متوسط، منخفض) كانت غير دالة احصائياً عند مستوى معنوية (0. . •)، كما بلغ متوسط الرتب لفئة الطلاب الذين كانت معدلات التحسن في المهارات البحثية لديهم مرتفعة (15.54) ومتوسط الرتب للفئة التي كانت معدلات تحسنها متوسطة (20.08) بينما بلـ للطلاب منخفضي معدلات التحسن (18.25) وهذه المتوسطات لا تظهر فروقات كبيرة في الرتب بين العينات الثلاث في في معدل التحسن في مهارات البحث العلمي. ويعكس ذلك عدم وجود فروق ذات

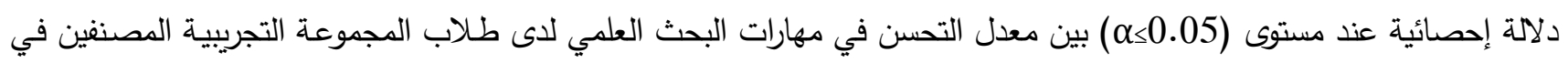

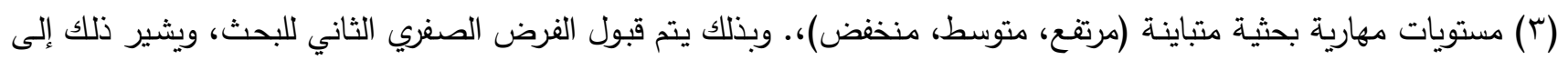

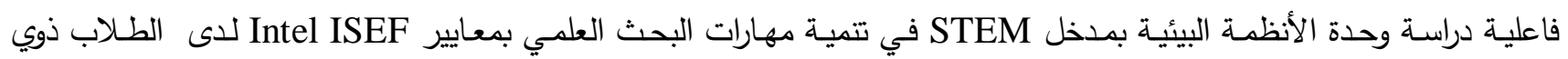
المستويات المهارية المتباينة.

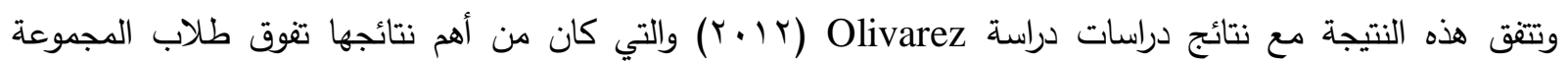
التجريبية الخاضعة لتعليم STEM على المجموعة المقارنة في التحصيل الدراسي في العلوم، والرياضيات، حيث كان المعلمون في دراني تدريس تعليم STEM يستخدمون طرائق تدريسية حديثة، مثل: التدريب العملي والتعلم المبني على المشروع العلمي، مما كان له أثر فئري

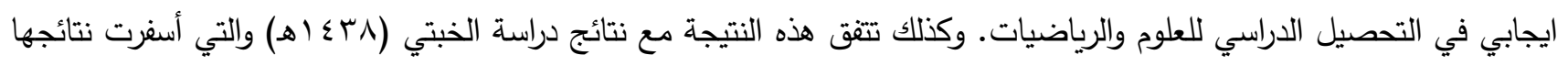

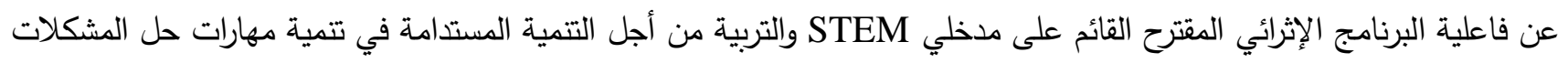

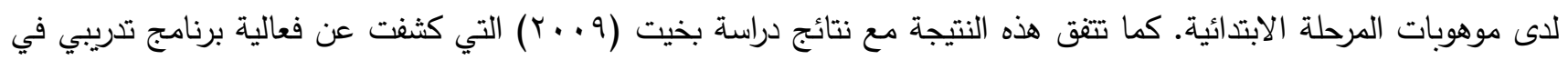

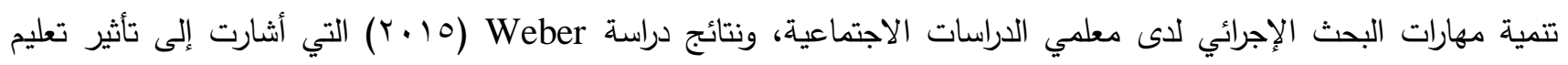
على المناهج الدراسية، وإن لم يكن على قدم المساواة في الددارس التي ليس بها تقنية. وكذلك تتفق هذه النتيجة مع نتائج

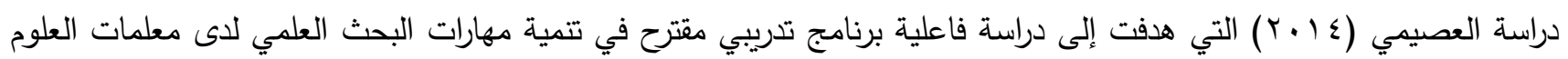
الطبيعية بالمرحلة الثانوي، وانعكاس أثر البرنامج على تتمية التفكير العلمي لدى طالباتهن بمدينة الطائف. وقد كان للبرنامج التدريبي الأثر الإيجابي في المعلمات والذي انعكس على طالباتهن، حيث لوحظ ارتفاع متوسط الأداء البعدي للطالبات على مقياس مهارات 
في ضوء ما تم التوصل إليه من نتائج، يمكن التوصية بما يلي: ا. ـ تأكيد أهمية تطوير تعليم العلوم في المرحلة الابتدائية باستخدام مدخل تعليم STEM لما له من فاعلية في تتمية مهارات

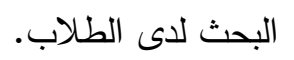

r. ت توفير كل التقنيات والبنية الأساسية من أجل تبني استخدام تعليم STEM لتدريس العلوم في العملية التعليمية.

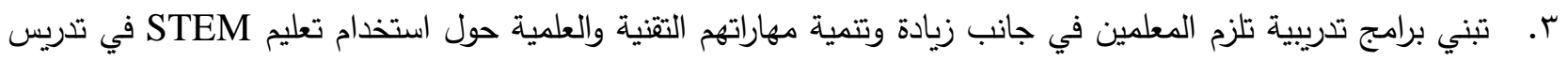
المواد العلمية. ع. استخدام تعليم STEM لتدريس العلوم في مراحل تعليمية أخرى. ه. ضرورة العمل على تدريب الطلاب نحو استخدام التصميم الهندسي في العملية التعليمية في مراحل تعليمية مبكرة.

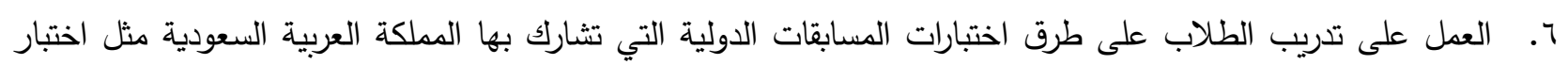
TEMMIS واختبار Intel ISEF، وذلك بوضع أنشطة مصاحبة بالمناهج التعليمية تحاكي أسئلة هذه المسابقات. V. تطوير مقررات العلوم من خلال تصميمها وفق تعليم STEM وتعليم STEAM.

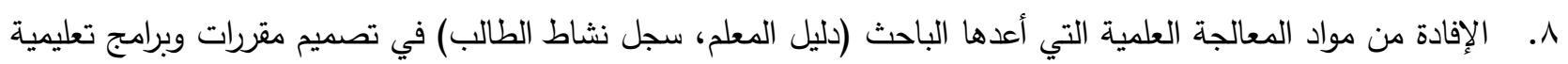
متمركزة حول STEM مول مواد

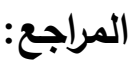 \\ أولاً: المراجع العربية:}

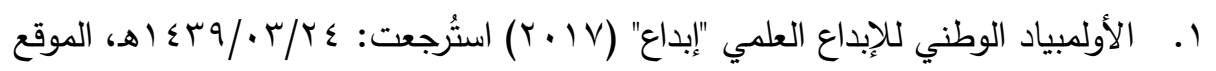
http://ibda.mawhiba.org/AboutUs/Pages/AboutUs.aspx

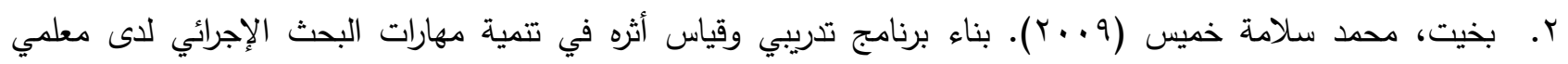

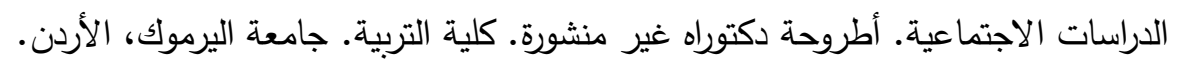

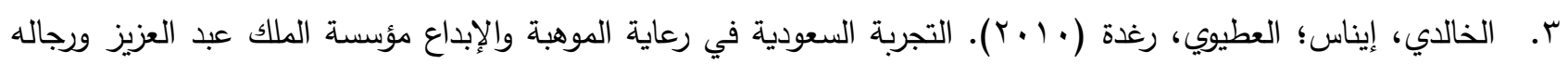

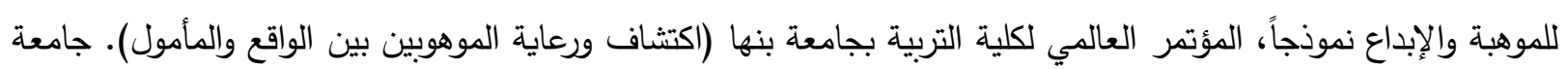
بنها، ص صو

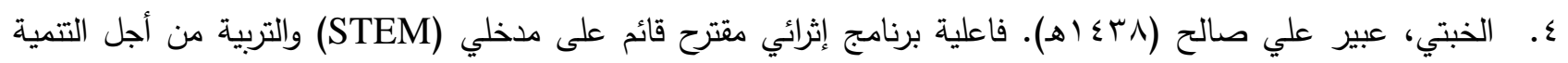

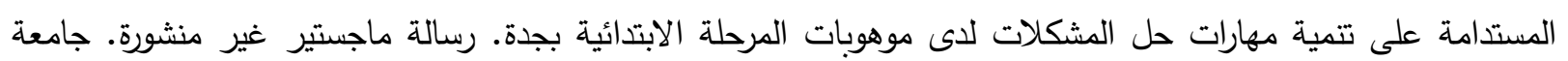
جدة، جدة. ه. الدوسري، هند مبارك (؟ب؟ (1). واقع تجربة المملكة العربية السعودية في تعليم STEM على ضوه التجارب الدولية. مؤتمر

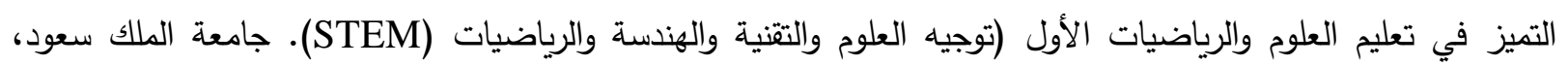
الرياض. 7. الرويلي، فواز عائد (7 ا • Y). أثر تدريس مادة العلوم باستخدام برنامج تعليمي مبني على مهارات البحث المستقل في تتمية التفكير الإبداعي لاى طلبة الصف الثالث المتوسط في محافظة القريات. رسالة ماجستير غير منشورة. كلية التربية. جامعة

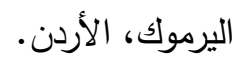

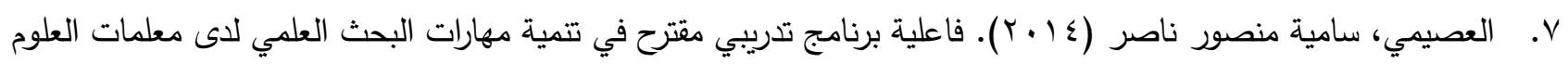

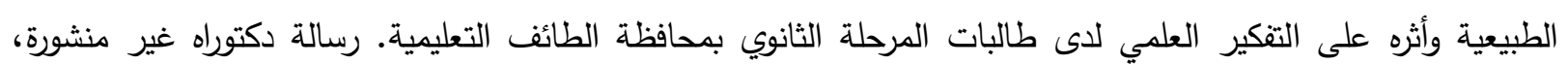
aे 
جامعة أم القرى، مكة المكرمة.

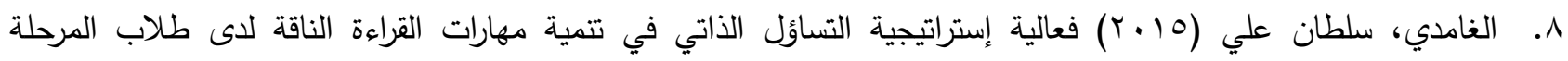
الثانوية. رسالة ماجستير غير منشورة، جامعة جدة، جدة المان.

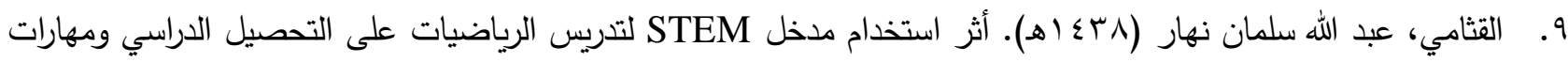
التفكير للى طلاب الصف الثاني المتوسط. رسالة دكتوراه غير منشورة. جامعة أم القرى، مكة المكرمة.

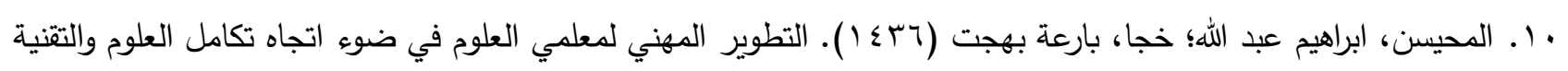
والهندسة والرياضيات STEM. مؤتمر التميز في تعليم العلوم والرياضيات الأول. (توجيه العلوم والتقنية والهندسة والرياضيات STEM)، جامعة الملك سعود، الرياض.

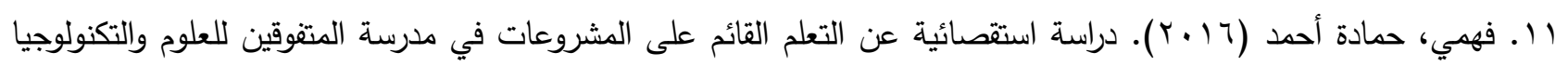
بمصر • دراسة حالة. رسالة ماجستير غير منشورة. الجامعة الأمريكية في القاهرة.

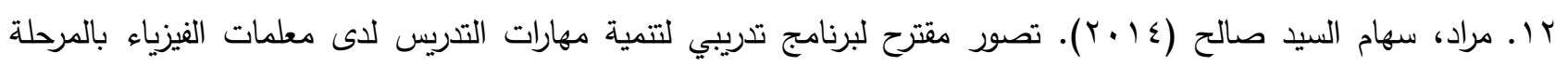

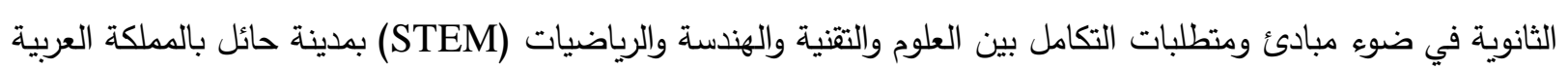

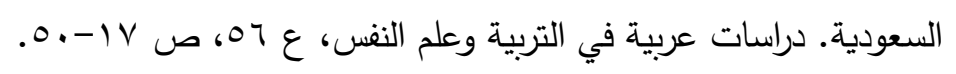

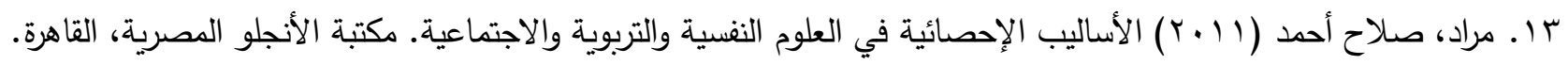

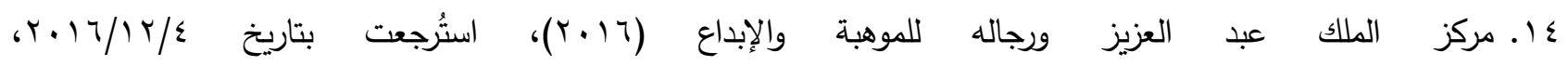

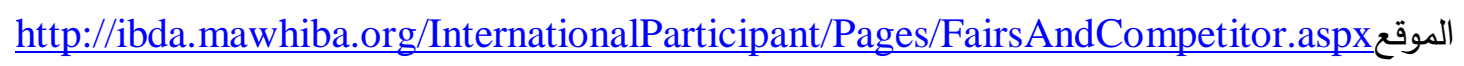
10. مشروع الملك عبد الله لتطوير التعليم (1) (هـ). مشروع الإستراتيجية الوطنية لتطوير التعليم العام. شركة تطوير للخدمات التعليمية. الرياض، وزارة التربية والتعليم بالمملكة العربية السعودية.

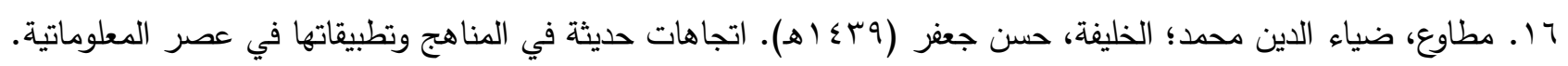
دار النشر الدولي. الرياض.

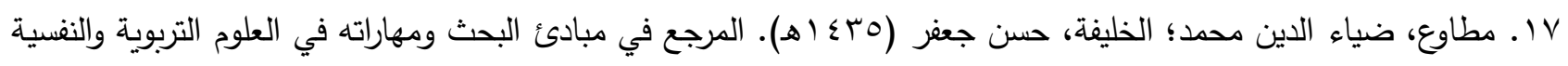
والاجتماعية. مكتبة المتتبي، الدمام.

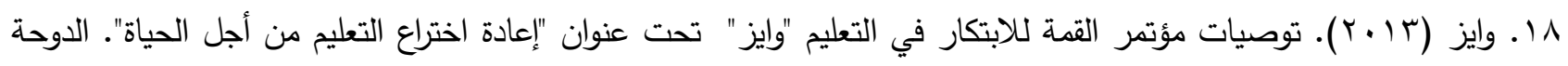

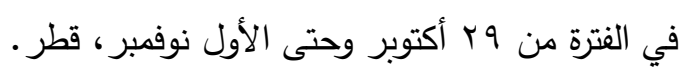

ثانياً: المراجع الأجنبية:

[1] W. McComas, (2014). The Language of Science Education: An Expanded Glossary of Key Terms and Concepts in Science Teaching and Learning. Rotterdam, AW: Sense Publishers.

[2] M. Weber, (2015). The role of globalization, science, technology, engineering, and mathematics project-based learning, and the national science and technology fair mandate in creating $21^{\text {st }}$ - century- ready students in schools in Costa Rica. A Dissertation Presented to Faculty at the University of Southern California's Rossier School of Education. University of Southern California.

[3] E. Williams \& J. Dugger, (2013). Evolution of STEM in the United States. International Technology and Engineering Educators Association. 


\title{
The Effect of Teaching Science by using STEM Approach in Developing Research Skills in Accordance with the ISEF Standards among Primary Stage Students
}

\author{
Majed Mohamed Hassan al-Malki \\ Department of Education Jeddah - Saudi Arabia \\ Joojooo1985@hotmail.com
}

\begin{abstract}
:
The aim of the research is to identify the effectiveness of teaching scientific concepts with the standards of the ISEF Intel model for the fifth grade students in Jeddah in order to find out the extent to which science curricula in the primary stage according to the nation's vision provide students with 21 st century skills, in particular scientific research skills.

The semi-experimental design of two groups (experimental and control groups) was chosen using pre- and post-tests according to the standards of the Intel ISEF competition. The students of the experimental group (30 students) studied the developed unit of environmental systems using the teacher's guide in the light of STEM to develop the research skills according to the standards of Intel ISEF, while the students of the control group (30 students) studied the unit with the usual teaching methods.

The results showed the following:

- There were statistically significant differences at $(\alpha \leq 0.05)$ between the average scores of the experimental group and the control group in the post-application used to test the skills of research according to the standards of the Intel ISEF competition, in favour of the experimental group.

- The magnitude of the impact according to the equation of the ETA square was (0.75), which refers to the significant effectiveness of the STEM approach in the development of scientific research skills in the light of standards of the Intel ISEF competition for the fifth grade students in Jeddah who studied the unit of environmental systems according to STEM.

- There were no statistically significant differences at $(\alpha \leq 0.05)$ between the average of improvement rate in the scientific research skills of the experimental group students with different skill levels (high, middle, low), indicating the effectiveness of studying the ecosystem unit through the STEM approach in the development of scientific research skills in the light of Intel ISEF standards for students with varying skill levels.

Based on the results of the research, it was recommended that the use of the STEM education approach should be generalized in the teaching of science curricula, because it is effective in developing the students' thinking and research skills. It was also recommended that the importance of creating the educational environment should be emphasized by providing the basic infrastructure for education, with using the STEM approach to teach science. Moreover, the results of the study revealed the necessity of training students in all stages on the methods of International Competitions Testing (ISEF) in which students from Saudi Arabia participate.
\end{abstract}

Keywords: Science, Primary stage, Stem (STEM). 